\title{
Development and Application of New Oxidation Systems Utilizing Oxometalate Catalysts
}

\author{
Hiromi Hamamoto ${ }^{\dagger}$ \\ School of Pharmaceutical Sciences, Kinki University; 3-4-1 Kowakae, \\ Higashi-Osaka 577-8502, Japan. \\ Received March 12, 2012
}

\begin{abstract}
This review describes our recent efforts in the development and application of new oxidation systems utilizing oxometalate catalysts. The novel use of heteropoly acid (HPA), an acidic oxometalate catalyst, in hypervalent iodine-mediated oxidations provided an effective strategy to generate cation radical species that enables a variety of direct $\mathrm{C}-\mathrm{H}$ functionalizations of aromatic compounds. This strategy brought a facile biaryl synthesis and new spirodienone syntheses in aromatic oxidation chemistry. Moreover, this strategy opens up a facile synthetic route to morphinandienone alkaloids. On the other hand, the use of oxometalate catalyst together with poly( $N$-isopropylacrylamide) (PNIPAAm)-based polymer in the development of new solid-phase catalyst provided a novel reaction system in water. Due to the characteristic temperature-responsive intelligence of PNIPAAm, this reaction system brought a remarkable acceleration of the reactivity and ease of catalyst recovering in catalytic oxidation that uses hydrogen peroxide or oxygen gas $\left(\mathrm{O}_{2}\right)$ as primary oxidant. In addition, the recovered solid-phase catalyst could be used for consecutive reactions without any significant loss of its catalytic efficacy.
\end{abstract}

Key words oxidation; oxometalate; polymer-supported reagent; hypervalent iodine reagent; catalyst; heteropoly acid

\section{Introduction}

Oxidation reactions are of fundamental importance in nature, and are key transformations in organic synthesis. ${ }^{1-5)}$ Although numerous oxidation methods have been developed during the past decade, there is a need for development of more efficient and environmentally friendlier catalytic oxidation methods in fine chemical and pharmaceutical syntheses.

Oxometalate compounds and polyoxometalate compounds are interesting catalyst materials due to their controllable acid and redox properties. ${ }^{6-32)}$ They can be used as acid and oxidation catalysts either in the solid sate or in solution. In addition, many oxometalate compounds and polyoxometalate compounds are readily available, inexpensive, and easy to handle. Therefore, they are suitable for the synthesis of bulk chemicals; indeed there are exant several large-scale commercialized processes using oxometalate catalysts. ${ }^{13,30-32)}$ On the other hand, oxometalate catalysts are now expected to provide efficient routes for the synthesis of fine chemicals and pharmaceuticals. This work focuses much attention on the novel use of oxometalate catalysts in the development of new oxidation systems in organic synthesis.

\section{Oxidative Coupling Reaction Using Heteropoly Acid} and Hypervalent Iodine Reagent

Heteropoly acids (HPAs) are useful oxometalate catalysts

†Present address: Faculty of Agriculture, Meijo University; 1-501 Shiogamaguchi, Tempaku-ku, Nagoya 468-8502, Japan. synthesized by combination of hydrogen and oxygen with certain metals and non-metals. Due to their unique physicochemical properties, they have attracted much attention, particularly over the last two decades. There are many structural types of HPAs, which have been reviewed in detail elsewhere. ${ }^{33,34)}$ Common and important HPAs and those used in the majority of catalytic applications are the most stable and easily available Keggin compounds. The Keggin HPAs comprise heteropoly anions of the formula $\left[\mathrm{XM}_{12} \mathrm{O}_{40}\right]^{n-}(\alpha$-isomer $)$, where $\mathrm{X}$ is the heteroatom $\left(\mathrm{P}^{5+}, \mathrm{Si}^{4+}\right.$, etc. $)$ and $\mathrm{M}$ the addendum atom $\left(\mathrm{Mo}^{6+}, \mathrm{W}^{6+}\right.$, etc. $)$. The structure of the heteropoly anion is composed of a central tetrahedron $\mathrm{XO}_{4}$ surrounded by 12 edge- and corner-sharing metal-oxygen octahedral $\mathrm{MO}_{6}$

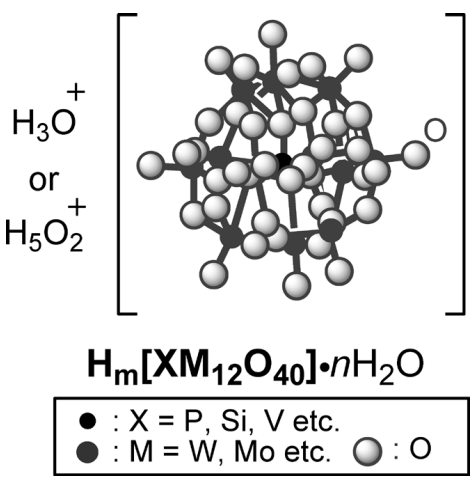

Fig. 1. Keggin-Type HPA 


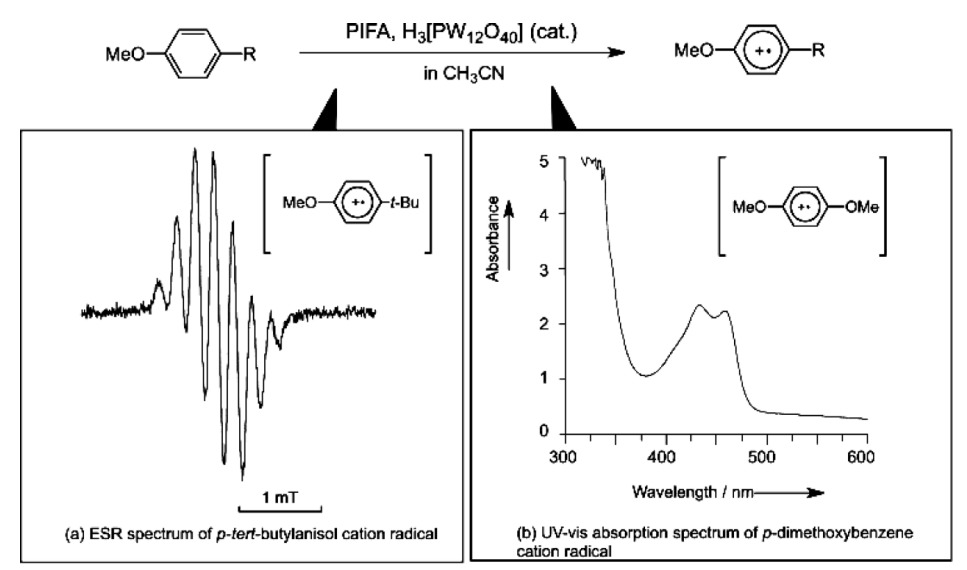

Chart 1. Generation of Cation Radical

moieties. Figure 1 shows the Keggin structure in polyhedral representation. Most typical Keggin HPAs such as $\mathrm{H}_{3} \mathrm{PW}_{12} \mathrm{O}_{40}$, $\mathrm{H}_{4} \mathrm{SiW}_{12} \mathrm{O}_{40}$, and $\mathrm{H}_{3} \mathrm{PMo}_{12} \mathrm{O}_{40}$ are commercially available.

The Keggin HPAs are usually insoluble in non-polar solvents but highly soluble in polar ones. Therefore they can be used as acid and oxidation catalysts either in heterogeneous or homogeneous conditions. In the case of acid catalyst, they behave like mineral acids having hydrated protons $\left(\right.$ as $\mathrm{H}_{3} \mathrm{O}^{+}$or $\mathrm{H}_{5} \mathrm{O}_{2}^{+}$) in protected environments and exhibit Brönsted acidity, which by several orders of magnitude is higher in strength than that of conventional mineral acids. ${ }^{35,36)}$ Keggin HPAs in heterogeneous system are generally more active catalysts than the conventional solid acid catalysts, which allows efficient operation under milder conditions. As a result, many new catalytic processes for organic syntheses based on their employment have been developed. On the other hand, Keggin HPAs in homogeneous system also have attracted interest because of their great softness of heteropolyanion (Keggin anions). The softness of heteropolyanion is assumed to play important roles in stabilizing organic intermediates. ${ }^{15,37,38)}$ In the present study, we focused on the utilization of the specific abilities of HPAs in solution for hypervalent iodine(III)-mediated oxidation systems.

Due to low toxicity, ready availability, easy handling, and reactivities similar to those of heavy metal reagents or anodic oxidation, hypervalent iodine reagents have attracted considerable research attention. ${ }^{39-77)}$ Since the early 1980 s, Kita and coworkers have revealed a wide array of reactivities for trivalent iodine reagents, such as phenyliodine(III) diacetate $\left(\mathrm{PhI}(\mathrm{OAc})_{2}, \quad \mathrm{PIDA}\right.$ or $\left.\mathrm{DIB}\right)$, phenyliodine(III) bis(trifluoroacetate) $\left(\mathrm{PhI}\left(\mathrm{OCOCF}_{3}\right)_{2}\right.$, PIFA or BIT), and they have developed many effective oxidation tools in organic synthesis. ${ }^{61-99)}$ Among these results, the single-electron-transfer (SET) oxidation method of electron-rich arenas using $\mathrm{PhI}\left(\mathrm{OCOCF}_{3}\right)_{2}$ in 1,1,1,3,3,3-hexafluoro-2-propanol (HFIP $)^{86)}$ or $\mathrm{PhI}\left(\mathrm{OCOCF}_{3}\right)_{2}-\mathrm{BF}_{3} \cdot \mathrm{Et}_{2} \mathrm{O}$ in $\mathrm{CH}_{2} \mathrm{Cl}_{2}{ }^{92)}$ is one of the most important works, and this method was applied to the synthesis of several biologically active natural products. In this work, we tried to utilize $\mathrm{PhI}\left(\mathrm{OCOCF}_{3}\right)_{2}-\mathrm{HPA}$ combination to design new oxidation systems via SET reaction. ${ }^{100,101)}$

2.1. Generation of Cation Radical Previously, Kita reported that PIFA reacted with $p$-substituted anisol to give a cation radical intermediate in a polar and poorly nucleophilic solvent such as 2,2,2-trifluoroethanol (TFE) or HFIP, and an activated hypervalent iodine reagent such as $\mathrm{PhI}\left(\mathrm{OCOCF}_{3}\right)_{2}-$ $\mathrm{BF}_{3} \cdot \mathrm{Et}_{2} \mathrm{O}$ or $\mathrm{PhI}\left(\mathrm{OCOCF}_{3}\right)_{2}-\mathrm{Me}_{3} \mathrm{SiOTf}$ in $\mathrm{CH}_{2} \mathrm{Cl}_{2}$ was similarly effective for the generation of cation radical intermediate. As an extension of these studies, we found the reaction of $\mathrm{PhI}\left(\mathrm{OCOCF}_{3}\right)_{2}-\mathrm{HPA}$ with $p$-tert-butylanisole also readily generates the stable cation radical species, which were detected by ESR spectroscopy (Chart 1a). The spectrum thus obtained was almost identical to that reported previously by us. ${ }^{86)}$ Additionally, UV spectrum of the reaction of dimethoxybenzene under the same reagent system also showed cation radical species which can be rationalized by absorption band between 400 and $600 \mathrm{~nm}$ (Chart 1b). ${ }^{86)}$ When HPA in the absence of $\mathrm{PhI}\left(\mathrm{OCOCF}_{3}\right)_{2}$ was used in these reactions, no cation radical species, could be observed in both UV and ESR spectra.

The methodology for generating a radical species using $\mathrm{PhI}\left(\mathrm{OCOCF}_{3}\right)_{2}-\mathrm{HPA}$ in $\mathrm{CH}_{3} \mathrm{CN}$ is practical, safe, and economical. We were thus prompted to apply this efficient process to the oxidative coupling reaction of various types of phenol ether derivatives.

Hiromi Hamamoto was born in Kyoto, Japan, in 1974. He received his B.S. (1998) and M.S. (2000) degrees from Okayama University and received his Ph.D. (2003) degree from Osaka University under the direction of Professor Yasuyuki Kita. He joined the group of Professor Shiro Ikegami at Teikyo University as a research associate (2003-2007). He moved to Kinki University as a lecturer (2007-2012) and he currently is an associate professor at Meijo University since 2012. He received the Pharmaceutical Society of Japan Award for a Young Chemist in 2011. His present research focuses on the development of novel synthetic methodology and its application to the synthesis of biologically important compounds.

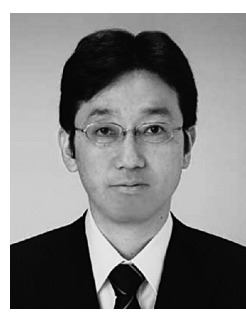

Hiromi Hamamoto 
2.2. Oxidative Non-phenolic Coupling Reaction Leading to Biaryls The oxidative aryl-aryl coupling reaction is an important strategy for construction of the biaryl skeleton, which is a key intermediate in the biosynthesis of many classes of natural products. ${ }^{102)} \mathrm{A}$ number of biogenetic-type arylaryl coupling reactions have been investigated using heavy metal oxidizing reagents such as mercury(II), thallium(III), vanadium(V), iron(III), manganese(IV), and ruthenium(IV) salts. ${ }^{103-108)}$ However, the yields are not always satisfactory. Moreover, heavy metal reagents are highly toxic and must be handled very carefully. Therefore, the development of more advantageous reagent conditions has been, and remains, a matter of interest.

On the other hand, oxidative aryl-aryl coupling reactions using hypervalent iodine(III) reagents, which are less toxic and easier to handle, have received much attention because their reactivities are similar to those of heavy metals. The hypervalent iodine(III) reagent, PIFA, induced biaryl coupling reaction involving aromatic cation-radical intermediates was originally developed by our group ${ }^{89,94,95,97)}$ and applied to the synthesis of some useful heterocycles by Moreno et al. ${ }^{109)}$ The commonly used conditions for biaryl coupling reactions using PIFA are as follows: (i) in poorly nucleophilic solvents such as TFE or HFIP; and (ii) in the presence of $\mathrm{BF}_{3} \cdot \mathrm{Et}_{2} \mathrm{O}$ (2 eq) in $\mathrm{CH}_{2} \mathrm{Cl}_{2}$.

In order to investigate the utility of $\mathrm{PhI}\left(\mathrm{OCOCF}_{3}\right)_{2}-\mathrm{HPA}$ in biaryl synthesis, the conversion of $N$-benzyl- $N$-phenethylamine derivative 1a to the dibenzazocine derivative 2a was initially studied; the results are shown in Table 1. Four HPAs, $\mathrm{H}_{3}\left[\mathrm{PW}_{12} \mathrm{O}_{40}\right], \mathrm{H}_{3}\left[\mathrm{PMo}_{12} \mathrm{O}_{40}\right], \mathrm{H}_{4}\left[\mathrm{SiW}_{12} \mathrm{O}_{40}\right]$, and $\mathrm{H}_{4}\left[\mathrm{SiMo}_{12} \mathrm{O}_{40}\right]$, were examined for their activation of $\mathrm{PhI}\left(\mathrm{OCOCF}_{3}\right)_{2}$ in the biaryl coupling reaction; all were found to give $\mathbf{2 a}$ in excellent yields under homogeneous conditions (entries 1-4). On the other hand, without HPA, 2a was obtained only in $4 \%$ yield and the starting material was recovered even after a long reaction time (entry 5). The reaction did not proceed when $\mathrm{H}_{3}\left[\mathrm{PMo}_{12} \mathrm{O}_{40}\right]$, which has the highest oxidation potential among the four HPAs, was used in the absence of PIFA (entry 6). Moreover, cyclization was also carried out under various conditions to determine the best coupling method: (a) $\mathrm{PhI}\left(\mathrm{OCOCF}_{3}\right)_{2}-\mathrm{BF}_{3} \cdot \mathrm{Et}_{2} \mathrm{O}$ in $\mathrm{CH}_{2} \mathrm{Cl}_{2}$; (b) $\mathrm{PhI}\left(\mathrm{OCOCF}_{3}\right)_{2}$ in HFIP; (c) thallium(III) tris(trifluoroacetate) (TTFA) (prepared in situ by combination of thallium(III) oxide with trifluoroacetic acid and its anhydride) ${ }^{[4 \mathrm{e}]}$; (d) ruthenium(IV) tetrakis(trifluoroacetate) (RUTFA) (prepared in situ by combination of ruthenium(IV) oxide with trifluoroacetic acid and its anhydride); and (e) vanadium(V) oxytrifluoride (entries 7-11). Although a considerable amount of the biaryl coupling product 2a was obtained in some cases, no other condition gave a higher yield than that by $\mathrm{PhI}\left(\mathrm{OCOCF}_{3}\right)_{2}-\mathrm{HPA}$. These results clearly indicate that the combination of $\mathrm{PhI}\left(\mathrm{OCOCF}_{3}\right)_{2}$ and HPA is the best condition for the oxidative biaryl coupling reaction.

One possible explanation for the remarkable control exerted by HPA is that HPA plays important roles not only in the activation of $\mathrm{PhI}\left(\mathrm{OCOCF}_{3}\right)_{2}$ but also in stabilizing the cation radical intermediate due to the greater softness of the heteropoly anion. ${ }^{110)}$ The better yield with one-electron oxidant, $\mathrm{VOF}_{3}$, which would more smoothly give the cation radical intermediate than the two electron oxidants such as thallium(III), ruthenium(IV), and hypervalent iodine(III), supports this explanation.

Similarly, reactions of other substrates such as the $N$-benzyl- $N$-phenethylamine derivatives, the $N, N$-dibenzylamine derivatives 1,3-diarylpropanes, the silaketal derivatives, and the diarylacrylate derivatives with $\mathrm{PhI}\left(\mathrm{OCOCF}_{3}\right)_{2}$ and tungsto(VI)

Table 1. Intramolecular Oxidative Coupling Reaction of 1a

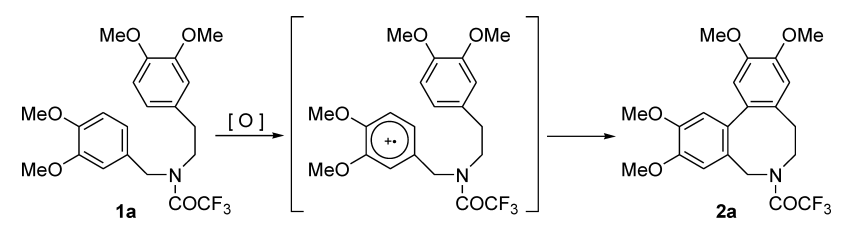

\begin{tabular}{|c|c|c|c|c|}
\hline Entry & Reagents and solvents & Temperature & Time & Yield $(\%)^{a)}$ \\
\hline 1 & $\begin{array}{l}\mathrm{PhI}\left(\mathrm{OCOCF}_{3}\right)_{2}, \\
\quad \mathrm{H}_{3}\left[\mathrm{PW}_{12} \mathrm{O}_{40}\right],{ }^{b)} \mathrm{CH}_{3} \mathrm{CN}\end{array}$ & $-20-0^{\circ} \mathrm{C}$ & $40 \mathrm{~min}$ & 97 \\
\hline 2 & $\begin{array}{l}\mathrm{PhI}\left(\mathrm{OCOCF}_{3}\right)_{2}, \\
\quad \mathrm{H}_{3}\left[\mathrm{PMo}_{12} \mathrm{O}_{40}\right], \mathrm{CH}_{3} \mathrm{CN}\end{array}$ & $-20-0^{\circ} \mathrm{C}$ & $40 \mathrm{~min}$ & 94 \\
\hline 3 & $\begin{array}{l}\mathrm{PhI}\left(\mathrm{OCOCF}_{3}\right)_{2}, \\
\quad \mathrm{H}_{4}\left[\mathrm{SiW}_{12} \mathrm{O}_{40}\right],{ }^{b)} \mathrm{CH}_{3} \mathrm{CN}\end{array}$ & $-20-0^{\circ} \mathrm{C}$ & $40 \mathrm{~min}$ & 94 \\
\hline 4 & $\begin{array}{l}\mathrm{PhI}\left(\mathrm{OCOCF}_{3}\right)_{2}, \\
\quad \mathrm{H}_{4}\left[\mathrm{SiMo}_{12} \mathrm{O}_{40}\right],{ }^{b} \mathrm{CH}_{3} \mathrm{CN}\end{array}$ & $-20-0^{\circ} \mathrm{C}$ & $40 \mathrm{~min}$ & 97 \\
\hline 5 & $\mathrm{PhI}\left(\mathrm{OCOCF}_{3}\right)_{2}, \mathrm{CH}_{3} \mathrm{CN}$ & $-20^{\circ} \mathrm{C}-\mathrm{rt}$ & $24 \mathrm{~h}$ & 4 \\
\hline 6 & $\mathrm{H}_{3}\left[\mathrm{PMo}_{12} \mathrm{O}_{40}\right],{ }^{c)} \mathrm{CH}_{3} \mathrm{CN}$ & $-20^{\circ} \mathrm{C}-\mathrm{rt}$ & $24 \mathrm{~h}$ & NR \\
\hline 7 & $\begin{array}{l}\mathrm{PhI}\left(\mathrm{OCOCF}_{3}\right)_{2}, \mathrm{BF}_{3} \cdot \mathrm{Et}_{2} \mathrm{O}, \\
\quad \mathrm{CH}_{2} \mathrm{Cl}_{2}\end{array}$ & $-40^{\circ} \mathrm{C}$ & $10 \mathrm{~min}$ & 68 \\
\hline 8 & $\mathrm{PhI}\left(\mathrm{OCOCF}_{3}\right)_{2}, \mathrm{HFIP}$ & $0^{\circ} \mathrm{C}$ & $6 \mathrm{~h}$ & 77 \\
\hline 9 & $\begin{array}{l}\mathrm{Tl}_{2} \mathrm{O}_{3}, \mathrm{BF}_{3} \cdot \mathrm{Et}_{2} \mathrm{O}, \\
\text { TFA,TFAA, } \mathrm{CH}_{2} \mathrm{Cl}_{2}\end{array}$ & $0^{\circ} \mathrm{C}$ & $2 \mathrm{~h}$ & 56 \\
\hline 10 & $\begin{array}{l}\mathrm{RuO}_{2}, \mathrm{BF}_{3} \cdot \mathrm{Et}_{2} \mathrm{O} \\
\text { TFA,TFAA, } \mathrm{CH}_{2} \mathrm{Cl}_{2}\end{array}$ & $0^{\circ} \mathrm{C}$ & $8 \mathrm{~h}$ & 45 \\
\hline 11 & $\mathrm{VOF}_{3}$, TFA, TFAA, $\mathrm{CH}_{2} \mathrm{Cl}_{2}$ & $-20^{\circ} \mathrm{C}$ & $4 \mathrm{~h}$ & 89 \\
\hline
\end{tabular}

a) Yield of isolated 2a. b) $200 \mathrm{mg} / \mathrm{mmol}$ c c) $2 \mathrm{~g} / \mathrm{mmol}$. 
phosphoric acid, $\mathrm{H}_{3}\left[\mathrm{PW}_{12} \mathrm{O}_{40}\right]$, which has the highest thermal and hydrolytic stability and the lowest oxidation potential among the four HPAs, gave the corresponding biaryl compounds in excellent yield (Tables 2-4). It is noteworthy that the silaketal moieties of $\mathbf{1} \mathbf{i}-\mathbf{k}$ were not cleaved during the reaction (Table 3).

2.3. Oxidative Non-phenolic Coupling Reaction Leading to Spirodienones The spirodienone unit is an important intermediate in the biosynthesis of many classes of natural products and occurs widely in nature. ${ }^{111)}$ Biosynthetically they are believed to be formed via coupling of diphenolic derivatives. ${ }^{112-118)}$ Many attempts to make spirodienones in vitro have been achieved by oxidative phenolic coupling reaction using heavy metal oxidizing reagents such as vanadium(V),
iron(III), manganese(IV), or thallium(III) salts, but unsatisfactory results were encountered in many cases. ${ }^{119-131)} \mathrm{Al}$ ternatively, phenolic coupling reactions using hypervalent iodine(III) reagents could also lead to spirodienones from para-substituted phenols $^{79,82,132-136)}$; however, phenolic instability often causes difficulties in smooth conversions. Therefore the development of effective routes to spirodienones remains an important topic in organic synthesis.

In contrast to oxidation of phenol derivatives, reactions of phenol ethers (i.e. non-phenolic coupling) to afford spirodienones would be more attractive because such approach using convenient and stable non-phenolic substrates could confer considerable advantages. ${ }^{100)}$ However, the treatment of phenol ethers with hypervalent iodine reagents is known

Table 2. Intramolecular Oxidative Coupling Reaction of $\mathbf{1 a}-\mathbf{h}$

\begin{tabular}{ccccccccc} 
& & & & \\
\hline
\end{tabular}

a) ca. $6 \mathrm{~mol} \%$. b) Yield of isolated product.

Table 3. Intramolecular Oxidative Coupling Reaction of $\mathbf{1 i - k}$

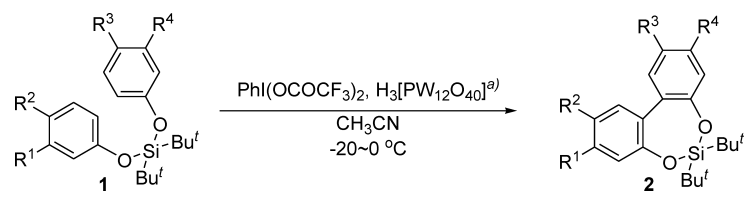

\begin{tabular}{|c|c|c|c|c|c|c|c|}
\hline Entry & Substrate & $\mathrm{R}^{1}$ & $\mathrm{R}^{2}$ & $\mathrm{R}^{3}$ & $\mathrm{R}^{4}$ & Product & Yield $(\%)^{b)}$ \\
\hline 1 & $1 \mathbf{i}$ & $\mathrm{OMe}$ & $\mathrm{OMe}$ & $\mathrm{OMe}$ & $\mathrm{OMe}$ & $2 \mathrm{i}$ & 94 \\
\hline 2 & $1 \mathrm{j}$ & $\mathrm{OMe}$ & $\mathrm{OMe}$ & \multicolumn{2}{|c|}{$-\mathrm{OCH}_{2} \mathrm{O}-$} & $2 \mathrm{j}$ & 86 \\
\hline 3 & $1 \mathrm{k}$ & \multicolumn{2}{|c|}{$-\mathrm{OCH}_{2} \mathrm{O}-$} & \multicolumn{2}{|c|}{$-\mathrm{OCH}_{2} \mathrm{O}-$} & $2 k$ & 93 \\
\hline
\end{tabular}

a) $c a .6 \mathrm{~mol} \% . b$ ) Yield of isolated product.

Table 4. Intramolecular Oxidative Coupling Reaction of 11-o

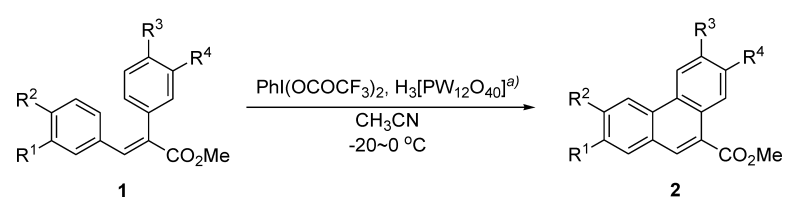

\begin{tabular}{|c|c|c|c|c|c|c|c|}
\hline Entry & Substrate & $\mathrm{R}^{1}$ & $\mathrm{R}^{2}$ & $\mathrm{R}^{3}$ & $\mathrm{R}^{4}$ & Product & Yield $(\%)^{b)}$ \\
\hline 1 & 11 & $\mathrm{OMe}$ & $\mathrm{OMe}$ & $\mathrm{OMe}$ & $\mathrm{OMe}$ & 21 & 93 \\
\hline 2 & $1 \mathrm{~m}$ & & & $\mathrm{OMe}$ & $\mathrm{OMe}$ & $2 \mathrm{~m}$ & 98 \\
\hline 3 & 1n & $\mathrm{OMe}$ & $\mathrm{OMe}$ & \multicolumn{2}{|c|}{$-\mathrm{OCH}_{2} \mathrm{O}-$} & $2 n$ & 93 \\
\hline 4 & 10 & \multicolumn{2}{|c|}{$-\mathrm{OCH}_{2} \mathrm{O}-$} & \multicolumn{2}{|c|}{$-\mathrm{OCH}_{2} \mathrm{O}-$} & 20 & 88 \\
\hline
\end{tabular}

a) $c a .6 \mathrm{~mol} \% . b$ ) Yield of isolated product. 


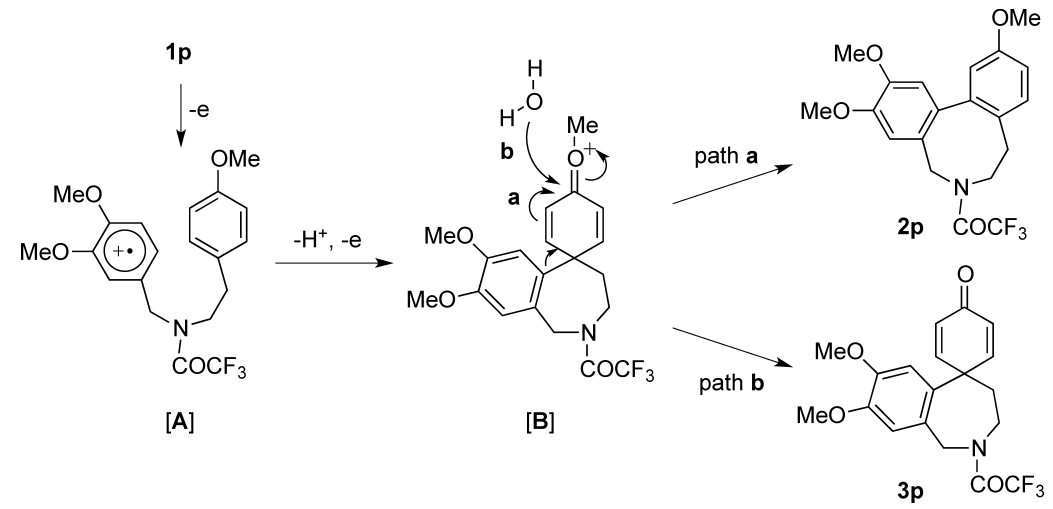

Chart 2. Possible Reaction Formation Mechanism of the Biaryls and Spirodienones

to give biaryl compounds and no method has so far been reported to give spirodienones. Thus reaction of norbelladine derivative 1 p with the previously described $\mathrm{PhI}\left(\mathrm{OCOCF}_{3}\right)_{2}-$ $\mathrm{BF}_{3} \cdot \mathrm{Et}_{2} \mathrm{O}$ reagent system in $\mathrm{CH}_{2} \mathrm{Cl}_{2}$ gave the biaryl (Table 5, entry 1). ${ }^{94)}$ On the other hand, reaction of $\mathbf{1 p}$ with the present $\mathrm{PhI}\left(\mathrm{OCOCF}_{3}\right)_{2}-\mathrm{HPA}$ reagent system in $\mathrm{CH}_{3} \mathrm{CN}$ afforded spirodienone $\mathbf{3 p}$ in $46 \%$ yield (entry 2). Exclusive formation of $3 \mathbf{p}$ occurred in good yield when the amount of HPA was increased (entries 3-6). The HPA used in these experiments is a hydrate; therefore it seemed likely that selective formation of spirodienone was due to the presence of water in the reaction medium. Indeed, selective formation of spirodienone 3p was observed when the reaction of $\mathbf{1 p}$ was carried out with $\mathrm{PhI}\left(\mathrm{OCOCF}_{3}\right)_{2}-\mathrm{BF}_{3} \cdot \mathrm{Et}_{2} \mathrm{O}$ in wet $\mathrm{CH}_{3} \mathrm{CN}$ (entry 7). We also investigated several other acid additives such as TfOH, TFA, montmorillonite K10, and Nafion-H; however, low yields and low selectivities were observed in most cases, and none of the conditions gave better results in terms of both the yield and selectivity than that given by $\mathrm{PhI}\left(\mathrm{OCOCF}_{3}\right)_{2}-\mathrm{HPA}$ (entries 9-12).

A plausible reaction mechanism leading to the biaryl $\mathbf{2 p}$ or spirodienone $\mathbf{3 p}$ is envisaged as follows (Chart 2). First, SET oxidation of the more electron-rich aromatic ring leads to intermediate [A]. Nucleophilic capture of [A] by the second aromatic ring gives intermediate [B]. The transformation of [B] into $\mathbf{2 p}$ occurs via dienone-phenol-type rearrangement (migration of the aryl group, path a), wheras $\mathbf{3 p}$ is formed through nucleophilic addition of $\mathrm{H}_{2} \mathrm{O}$, which is present in the vicinity of the electrophilic site as water of hydration of HPA (path b).

The generality of the direct formation of spirodienones from phenol ethers using $\mathrm{PhI}\left(\mathrm{OCOCF}_{3}\right)_{2}-\mathrm{H}_{4}\left[\mathrm{SiW}_{12} \mathrm{O}_{40}\right]$ in $\mathrm{CH}_{3} \mathrm{CN}$ was examined using the $N$-benzyl- $N$-phenethyl-amine derivative 1p, $N, N$-dibenzylamine derivative 1q, and diaryl propanes $1 \mathbf{r}-\mathbf{t}$ as shown in Table 6 . In all cases, the desired spirodienones were selectively obtained in good yields.

Treatment of the highly substituted phenol ether 1a under conditions leading to spirodienones provided biaryl 2a as the major product, along with $11 \%$ of $\mathbf{3 a}$ (Chart 3). This implies that the intramolecular coupling reaction of the dimethoxyphenyl derivatives such as the substrates shown in Table 2 proceeds via both intermediates [C] and [D] (Chart 4).

Table 5. Intramolecular Oxidative Coupling Reaction of $\mathbf{1 p}$

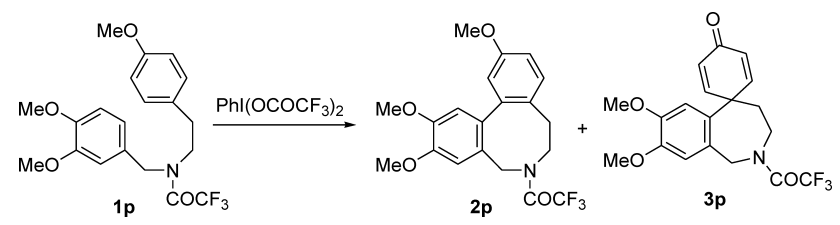

\begin{tabular}{|c|c|c|c|c|c|c|}
\hline \multirow{2}{*}{ Entry } & \multirow{2}{*}{ Additive } & \multirow{2}{*}{ Solvent } & \multirow{2}{*}{ Temperature } & \multirow{2}{*}{ Time } & \multicolumn{2}{|c|}{ Yield $(\%)^{e)}$} \\
\hline & & & & & $2 p$ & $3 p$ \\
\hline 1 & $\mathrm{BF}_{3} \cdot \mathrm{Et}_{2} \mathrm{O}$ & $\mathrm{CH}_{2} \mathrm{Cl}_{2}$ & $10 \mathrm{~min}$ & $-40^{\circ} \mathrm{C}$ & 89 & 0 \\
\hline 2 & $\mathrm{H}_{3}\left[\mathrm{PW}_{12} \mathrm{O}_{40}\right]^{a)}$ & $\mathrm{CH}_{3} \mathrm{CN}$ & $40 \mathrm{~min}$ & $-20-0^{\circ} \mathrm{C}$ & 36 & 46 \\
\hline 3 & $\mathrm{H}_{3}\left[\mathrm{PMo}_{12} \mathrm{O}_{40}\right]^{b)}$ & $\mathrm{CH}_{3} \mathrm{CN}$ & $40 \mathrm{~min}$ & $-40-0^{\circ} \mathrm{C}$ & 0 & 68 \\
\hline 4 & $\mathrm{H}_{3}\left[\mathrm{PMo}_{12} \mathrm{O}_{40}\right]^{b)}$ & $\mathrm{CH}_{3} \mathrm{CN}$ & $40 \mathrm{~min}$ & $-40-0^{\circ} \mathrm{C}$ & 0 & 72 \\
\hline 5 & $\mathrm{H}_{4}\left[\mathrm{SiW}_{12} \mathrm{O}_{40}\right]^{b)}$ & $\mathrm{CH}_{3} \mathrm{CN}$ & $40 \mathrm{~min}$ & $-40-0^{\circ} \mathrm{C}$ & 0 & 74 \\
\hline 6 & $\mathrm{H}_{4}\left[\mathrm{SiMo}_{12} \mathrm{O}_{40}\right]^{b)}$ & $\mathrm{CH}_{3} \mathrm{CN}$ & $40 \mathrm{~min}$ & $-40-0^{\circ} \mathrm{C}$ & 0 & 66 \\
\hline 7 & $\mathrm{BF}_{3} \cdot \mathrm{Et}_{2} \mathrm{O}$ & $\left.\mathrm{CH}_{3} \mathrm{CN}^{d}\right)$ & $30 \mathrm{~min}$ & $-40^{\circ} \mathrm{C}$ & 7 & 44 \\
\hline 8 & (none) & $\mathrm{CH}_{3} \mathrm{CN}^{d)}$ & $12 \mathrm{~h}$ & $-40^{\circ} \mathrm{C}-\mathrm{rt}$ & 9 & $7^{f}$ \\
\hline 9 & $\mathrm{TfOH}$ & $\mathrm{CH}_{3} \mathrm{CN}^{d)}$ & $30 \mathrm{~min}$ & $-40^{\circ} \mathrm{C}$ & 25 & 42 \\
\hline 10 & TFA & $\mathrm{CH}_{3} \mathrm{CN}^{d)}$ & $12 \mathrm{~h}$ & $-40^{\circ} \mathrm{C}-\mathrm{rt}$ & 14 & $19^{f}$ \\
\hline 11 & MK $10^{c}$ & $\mathrm{CH}_{3} \mathrm{CN}^{d)}$ & $12 \mathrm{~h}$ & $-40^{\circ} \mathrm{C}-\mathrm{rt}$ & 18 & $27^{f}$ \\
\hline 12 & Nafion-H & $\mathrm{CH}_{3} \mathrm{CN}^{d)}$ & $12 \mathrm{~h}$ & $-40^{\circ} \mathrm{C}-\mathrm{rt}$ & 16 & $23^{f}$ \\
\hline
\end{tabular}

a) $0.2 \mathrm{~g} / \mathrm{mmol}$. b) $0.8 \mathrm{~g} / \mathrm{mmol}$. c) MK 10: montmorillonite $\mathrm{K} 10 . d$ ) In wet $(0.3 \%) \mathrm{CH}_{3} \mathrm{CN}$. e) Yield of isolated products. $f$ ) Starting material was also isolated. 
Table 6. Intramolecular Oxidative Coupling Reaction of 1p-t

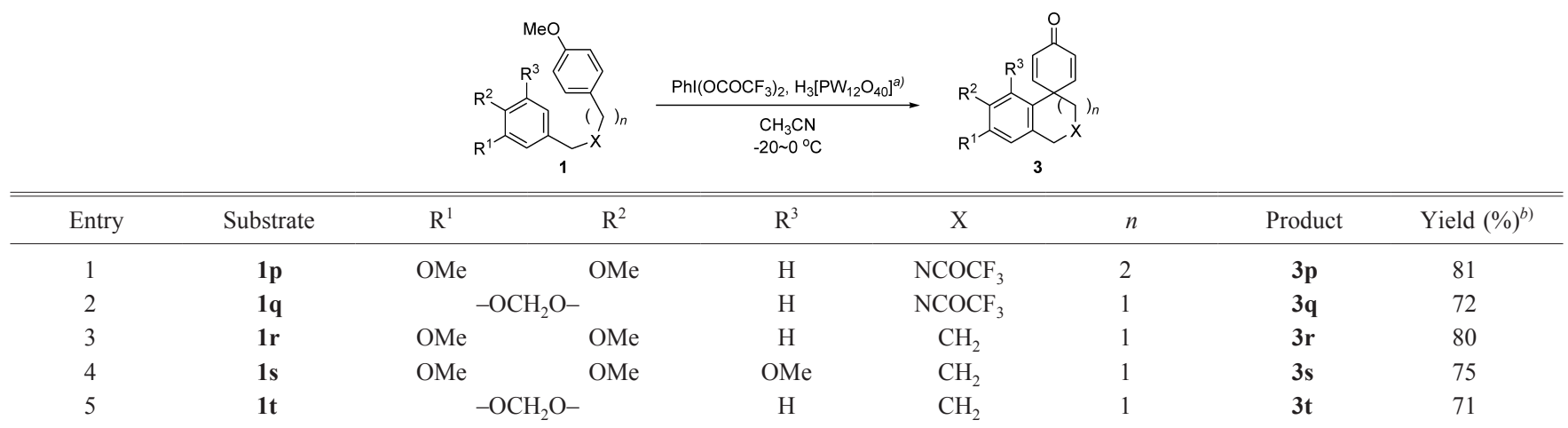

a) $0.8 \mathrm{~g} / \mathrm{mmol}$. b) Yield of isolated product.

\subsection{Efficient Synthesis of Morphinandienone Alkaloid}

The oxidation of benzyltetrahydroisoquinoline derivatives is the key reaction in the synthesis of several types of alkaloids and has received considerable attention since the first indication of biosynthetic importance of this type of reaction by Barton and Cohen in 1957..11-137) Much of this attention has been focused on the transformation into morphinandienonetype alkaloids. ${ }^{138-146)}$ In the early studies, the biomimetic phenolic coupling reaction using chemical oxidants or some other synthetic methods such as the Pschorr reaction, photochemical coupling reaction, or benzyne reaction, were continually employed. Despite large efforts, the yields of the coupling step were usually low and, in general, these methodologies did not afford practical routes to morphinandienone alkaloids.

However, a notable exception to those low yields was reported by Miller in 1971. ${ }^{147}$ ) They investigated an electrooxidative method and reported successful conversion of non-phenolic benzyltetrahydroisoquinoline to morphinandienones. ${ }^{148-150)}$ Such approaches using convenient and stable non-phenolic substrates were found to have a significant advantage in the synthesis of morphinandienones and other spirodienone alkaloids. Since then, much attention has been focused on the chemical oxidation of non-phenolic substrates toward morphinandienone synthesis. ${ }^{151,152)}$ Although two types of efficient non-phenoic coupling reactions, one leading to neospirinedienone alkaloids and one to aporphinic alkaloids, have been developed, transformation into morphinandienones using chemical oxidation has not yet been accomplished.

As part of our continuing efforts to establish a concise and general synthesis of spirodienone type alkaloids using $\mathrm{PhI}\left(\mathrm{OCOCF}_{3}\right)_{2}-\mathrm{HPA}$, the chemical oxidation of non-phenolic benzyltetrahydroisoquinoline toward morphinandienone synthesis was investigated. ${ }^{153,154)}$ The study was performed on a commercially available compound, laudanosine (4a) (Table 7). As for the chemical oxidation of $\mathbf{4 a}$ using heavy metals, glaucine (6a) was usually obtained in moderate-to-good yield. Similar to heavy metal oxidation, reaction of $\mathbf{4 a}$ with $\mathrm{PhI}\left(\mathrm{OCOCF}_{3}\right)_{2} / \mathrm{BF}_{3} \cdot \mathrm{Et}_{2} \mathrm{O}$ in $\mathrm{CH}_{2} \mathrm{Cl}_{2}$ gave $\mathbf{6 a}$ in $58 \%$ yield (entry 1). Contrariwise, the reaction using $\mathrm{PhI}\left(\mathrm{OCOCF}_{3}\right)_{2}-$ HPA (ca. $0.25 \mathrm{~mol} \% ; 20 \mathrm{mg} / \mathrm{mL})$ gave neither $o$-methyl flavinantine (5a) nor 6a (entry 2). One possible factor leading to this undesirable result is the influence of the tertiary amine. It is well known that the basicity of the nitrogen atom can play an important role in oxidation of tetrahydroisoquinoline derivatives, and deactivation of the nitrogen atom often

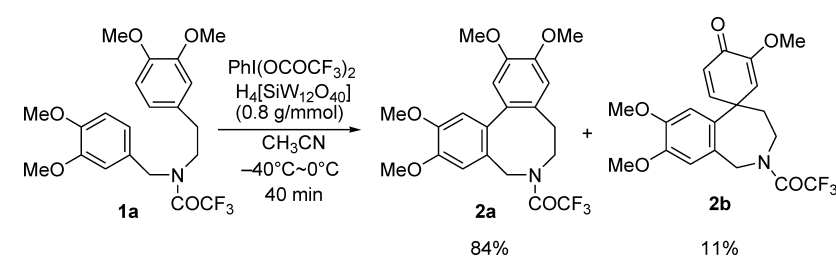

Chart 3. Intramolecular Oxidative Coupling Reaction of 1a Using PIFA- $\mathrm{H}_{4}\left[\mathrm{SiW}_{12} \mathrm{O}_{40}\right]$

has an influence on the course of the coupling reaction. ${ }^{111}$ To reduce the basicity of the nitrogen atom, the amount of HPA was increased; successful synthesis of $\mathbf{5 a}$ was thus achieved (entries 3,4). Alternatively, some acid additives to $\mathrm{PhI}\left(\mathrm{OCOCF}_{3}\right)_{2}-\mathrm{H}_{3}\left[\mathrm{PW}_{12} \mathrm{O}_{40}\right]$ were investigated for the same purpose. ${ }^{155)}$ In all cases, dominant formation of $\mathbf{5 a}$ was observed; exclusive formation of $\mathbf{5 a}$ in excellent yield occurred by using strong acid additive such as $\mathrm{BF}_{3} \cdot \mathrm{Et}_{2} \mathrm{O}$ (entry 5 ). This is the first example effectively to produce morphinandienones using chemical oxidation. Other commercially available HPAs such as $\mathrm{H}_{3}\left[\mathrm{PMo}_{12} \mathrm{O}_{40}\right], \mathrm{H}_{4}\left[\mathrm{SiW}_{12} \mathrm{O}_{40}\right]$, and $\mathrm{H}_{4}\left[\mathrm{SiMo}_{12} \mathrm{O}_{40}\right]$ were also examined for this reaction, and all were found to give $\mathbf{5 a}$ in good-to-excellent yields (entries 6-8). To achieve the coupling reaction with simple reaction procedure, the novel use of HPA supported on silica gel, which is prepared by known method, ${ }^{156)}$ was demonstrated and gave sufficient yield (entry 9). Additionally, the reaction was carried out in the absence of HPA in wet solvent and also afforded 5a. However, the yield of 5a decreased and an inseparable mixture was obtained (entries 10,11). This indicates that the presence of water plays an important role in producing $\mathbf{5 a}$, and the hydration water of HPA, which is present in the vicinity of the electrophilic site, has a stabilizing effect on the cation radical species due to the greater softness of the HPA anion, and may cause a preference for efficiently yielding $\mathbf{5 a}$.

A plausible reaction mechanism leading to $\mathbf{5 a}$ and $\mathbf{6 a}$ is envisaged as follows (Chart 5). First, SET oxidation of the electron-rich aromatic ring leads to intermediate [E]. The formation of $\mathbf{5 a}$ would be introduced by hydration of the intermediate [F]. On the other hand, as for $\mathbf{6 a}$, there are two possible pathways: direct $o-p$ coupling (path c) $v$ s. bridgehead $p-p$ coupling via intermediate $[\mathrm{F}]$ and $[\mathrm{G}]$ followed by rearrangement (path d). In view of the isolation of $\mathbf{5 a}$ and the absence of 6a in entry 11, it seems reasonable to suggest that $\mathbf{6 a}$ is formed by path $\mathrm{d}$. 


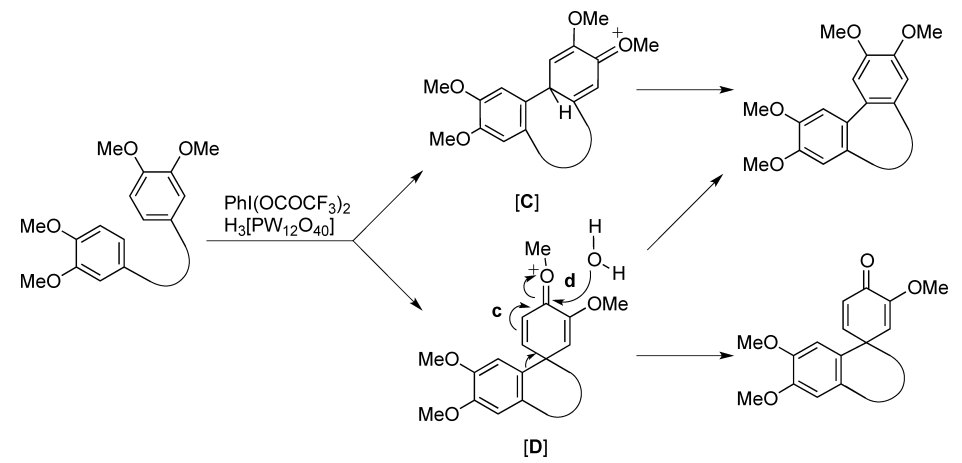

Chart 4. Possible Mechanism for the Reaction of the Highly Substituted Substrates

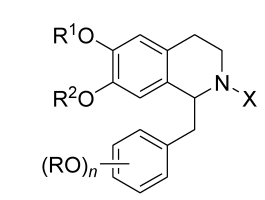

benzyltetrahydroisoquinoline

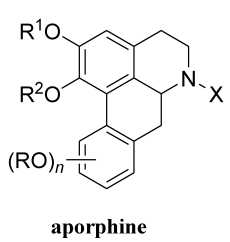

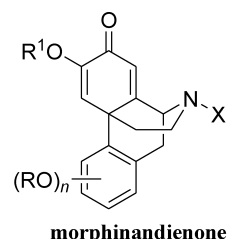

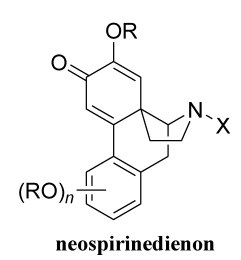

Fig. 2. Some Important Isoquinoline and Related Alkaloids

The remarkable result obtained in the reaction of $\mathbf{4 a}$ prompted us to extend our procedure to several morphinandienone syntheses from benzyltetrahydroisoquinoline derivatives $(\mathbf{4 b}-\mathbf{f})$. $\quad \mathrm{PhI}\left(\mathrm{OCOCF}_{3}\right)_{2}-\mathrm{HPA}-\mathrm{BF}_{3} \cdot \mathrm{Et}_{2} \mathrm{O}$ and the high-yield conversion to morphinandienone derivatives such as flavinantine, amurine, and pallidine was accomplished (Table 8). Alternatively, oxidation of $N$-protected benzyltetrahydroisoquinoline derivatives, $N$-trifluoroacetylnorlaudanosine (4g), was also investigated (Table 9). When the reaction was carried out with $\mathrm{PhI}\left(\mathrm{OCOCF}_{3}\right)_{2}-\mathrm{BF}_{3} \cdot \mathrm{Et}_{2} \mathrm{O}$, formation of neospirinedienone (7g) was observed, similar to heavy metal oxidation. ${ }^{151)}$ On the contrary, the use of novel reagent combination, $\mathrm{PhI}\left(\mathrm{OCOCF}_{3}\right)_{2}-\mathrm{HPA}$, afforded $N$-trifluoroacetylnorsebiferine $\mathbf{5 g}$ ) and dominant formation of $\mathbf{5} \mathbf{g}$ occurred in the presence of wet acetonitrile.

It is noteworthy that the reaction proceeds in such mild condition with simple experimental protocol. To make sure the effects of water, $\mathrm{PhI}\left(\mathrm{OCOCF}_{3}\right)_{2}-\mathrm{HPA}$-mediated reaction was carried out under anhydrous conditions and exclusive formation of $7 \mathrm{~g}$ were encountered. We also carried out the reaction with $\mathrm{PhI}\left(\mathrm{OCOCF}_{3}\right)_{2}-\mathrm{BF}_{3} \cdot \mathrm{Et}_{2} \mathrm{O}$ in wet acetonitrile and formation of $\mathbf{5 g}$ was observed. These results therefore suggest that the presence of water in the reaction medium plays an important role in its selectivity.

A plausible reaction mechanism leading to $\mathbf{5 g}$ and $\mathbf{7 g}$ is envisaged as follows (Chart 6). Initial SET oxidation of the aromatic ring reads to intermediate $[\mathrm{H}]$. Nucleophilic capture of $[\mathrm{H}]$ by the second aromatic ring gives intermediate [I]. Transformation of [I] into $\mathbf{5} \mathbf{g}$ occurs through nucleophilic addition of $\mathrm{H}_{2} \mathrm{O}$ (path e), wheeas $\mathbf{7 g}$ is formed by rearrangement of [I] via path $\mathrm{f}$.
To investigate the generality of this selectivity, oxidative cyclization of some other substrates (4) was also examined (Table 10). Similarly, treatment with $\mathrm{PhI}\left(\mathrm{OCOCF}_{3}\right)_{2}-\mathrm{HPA}$ in wet acetonitrile afforded morphinandienonetype products (5), wheras $\mathrm{PhI}\left(\mathrm{OCOCF}_{3}\right)_{2}-\mathrm{BF}_{3} \cdot \mathrm{Et}_{2} \mathrm{O}$ in dry acetonitrile produced neospirinedienone-type products (7).

2.5. Synthesis of Spirodienone Ethers and Spirodienone Lactones Spirodienone lactones and spirodienone ethers are regarded as a group of valuable compounds for the synthesis of many pharmaceutically and agriculturally valuable compounds. ${ }^{157-160)}$ Generally, these are synthesized by oxidative (biomimetic) phenolic coupling reaction; a large number of reagents for this purpose have been developed. ${ }^{161-164)}$ In contrast to the oxidation of phenol derivatives, the use of phenyl ethers for oxidative aromatic nucleophilic substitution reaction could be efficient alternatives to afford spirodienone lactones and spirodienone ethers; however, early investigations using heavy metal reagents reported low yields. ${ }^{165)}$

To investigate the utility of $\mathrm{PhI}\left(\mathrm{OCOCF}_{3}\right)_{2}-\mathrm{HPA}$ in the intramolecular oxidative cyclization reaction of phenyl ethers to oxygen heterocycles, oxidation of 3-(3,4-dimethoxyphenyl)propionic acid (8a) using various oxidation systems was examined (Table 11). ${ }^{166)}$ When the reaction was carried out with $\mathrm{PhI}\left(\mathrm{OCOCF}_{3}\right)_{2}$ in HFIP or $\mathrm{PhI}\left(\mathrm{OCOCF}_{3}\right)_{2}-\mathrm{BF}_{3} \cdot \mathrm{Et}_{2} \mathrm{O}$ in $\mathrm{CH}_{2} \mathrm{Cl}_{2}$, low yields and low selectivity of the spirodienone lactone were observed (entries 3, 4). Reaction with a heavy metal oxidizing reagent, such as vanadium(V) oxytrifluoride, did not afford the desired product (entries 1, 2). However, addition of $\mathrm{H}_{2} \mathrm{O}$ in the presence of activated $\mathrm{PhI}\left(\mathrm{OCOCF}_{3}\right)_{2}$ showed improvement of both the selectivity and yield (entries $5,6)$. The further optimization of acid activator indicates the effectiveness of the novel reagent system, $\mathrm{PhI}\left(\mathrm{OCOCF}_{3}\right)_{2}-$ $\mathrm{H}_{4}\left[\mathrm{SiW}_{12} \mathrm{O}_{40}\right]$, in this selective cyclization (entries 6-10). Since preparation of such oxygen-substituted spirodienone lactones is generally difficult in spite of their synthetic utilities, it is noteworthy that the conversion was smoothly achieved using such a simple method. Having obtained the remarkable results described above, we further extended our procedure to other series of aromatic carboxylic acid derivatives. Similarly, significant formation of spirodienone lactone in good yield was observed in each case (Table 12).

Further application of $\mathrm{PhI}\left(\mathrm{OCOCF}_{3}\right)_{2}-\mathrm{HPA}$ to the synthesis of spirodienone ethers was also examined using various alcohols 8k-r (Table 13). ${ }^{167,168)}$ When a symmetrical spirodienone was produced, the yield was good (entries 1-6). Even when the substrate contains other functional groups (alcohol, ester), the corresponding spirodienone was obtained in moderate 
Table 7. Oxidative Coupling Reaction of Laudanosine (4a)

\begin{tabular}{|c|c|c|c|c|c|c|c|}
\hline & & laudanosine (4a) & & O-methylflavinantine $(\mathbf{5 a})$ & glaucine ( & & \\
\hline Entry & Additive (5.0 eq) & $\mathrm{HPA}^{a)}(\mathrm{mg} / \mathrm{mL})$ & Solvent & Temperature & Time & 5a $(\%)^{b)}$ & 6a $(\%)^{b)}$ \\
\hline 1 & $\mathrm{BF}_{3} \cdot \mathrm{Et}_{2} \mathrm{O}$ & None & $\mathrm{CH}_{2} \mathrm{Cl}_{2}$ & $-40^{\circ} \mathrm{C}$ & $10 \mathrm{~min}$ & - & 58 \\
\hline 2 & None & $25(\mathrm{PW})$ & $\mathrm{CH}_{3} \mathrm{CN}$ & $-20-0^{\circ} \mathrm{C}$ & $12 \mathrm{~h}$ & - & - \\
\hline 3 & None & $100(\mathrm{PW})$ & $\mathrm{CH}_{3} \mathrm{CN}$ & $-20-0^{\circ} \mathrm{C}$ & $1 \mathrm{~h}$ & 67 & - \\
\hline 4 & None & $150(\mathrm{PW})$ & $\mathrm{CH}_{3} \mathrm{CN}$ & $-20-0^{\circ} \mathrm{C}$ & $1 \mathrm{~h}$ & 70 & - \\
\hline 5 & $\mathrm{BF}_{3} \cdot \mathrm{Et}_{2} \mathrm{O}$ & $25(\mathrm{PW})$ & $\mathrm{CH}_{3} \mathrm{CN}$ & $-20-0^{\circ} \mathrm{C}$ & $30 \mathrm{~min}$ & 90 & - \\
\hline 6 & $\mathrm{BF}_{3} \cdot \mathrm{Et}_{2} \mathrm{O}$ & 25 (PMo) & $\mathrm{CH}_{3} \mathrm{CN}$ & $-20-0^{\circ} \mathrm{C}$ & $30 \mathrm{~min}$ & 84 & - \\
\hline 7 & $\mathrm{BF}_{3} \cdot \mathrm{Et}_{2} \mathrm{O}$ & $25(\mathrm{SiW})$ & $\mathrm{CH}_{3} \mathrm{CN}$ & $-20-0^{\circ} \mathrm{C}$ & $30 \mathrm{~min}$ & 71 & - \\
\hline 8 & $\mathrm{BF}_{3} \cdot \mathrm{Et}_{2} \mathrm{O}$ & 25 (SiMo) & $\mathrm{CH}_{3} \mathrm{CN}$ & $-20-0^{\circ} \mathrm{C}$ & $30 \mathrm{~min}$ & 66 & - \\
\hline 9 & $\mathrm{BF}_{3} \cdot \mathrm{Et}_{2} \mathrm{O}$ & $\begin{array}{c}\mathrm{PW} \text { on } \mathrm{SiO}_{2} \\
\quad(0.3 \mathrm{eq})^{c)}\end{array}$ & $\mathrm{CH}_{3} \mathrm{CN}$ & $-20-0^{\circ} \mathrm{C}$ & $30 \mathrm{~min}$ & 87 & - \\
\hline 10 & $\mathrm{BF}_{3} \cdot \mathrm{Et}_{2} \mathrm{O}$ & None & $\begin{array}{c}0.5 \% \mathrm{H}_{2} \mathrm{O} / \\
\mathrm{CH}_{3} \mathrm{CN}\end{array}$ & $-20-0^{\circ} \mathrm{C}$ & $1 \mathrm{~h}$ & 41 & - \\
\hline 11 & $\mathrm{BF}_{3} \cdot \mathrm{Et}_{2} \mathrm{O}$ & None & $\begin{array}{c}1 \% \mathrm{MeOH} / \\
\mathrm{CH}_{2} \mathrm{Cl}_{2}\end{array}$ & $-20-0^{\circ} \mathrm{C}$ & $1 \mathrm{~h}$ & 41 & - \\
\hline
\end{tabular}

a) $\mathrm{PW}=\mathrm{H}_{3}\left[\mathrm{PW}_{12} \mathrm{O}_{40}\right] ; \mathrm{PMo}=\mathrm{H}_{3}\left[\mathrm{PMo}_{12} \mathrm{O}_{40}\right] ; \mathrm{SiW}=\mathrm{H}_{4}\left[\mathrm{SiW}_{12} \mathrm{O}_{40}\right] ; \mathrm{SiMo}=\mathrm{H}_{4}\left[\mathrm{SiMo}_{12} \mathrm{O}_{40}\right]$. $b$ ) Yield of isolated products. $c$ ) $\mathrm{PW}$ on $\mathrm{SiO} \mathrm{O}_{2}=20 \mathrm{wt} \%$ supported on silica gel $($ see ref. 156).

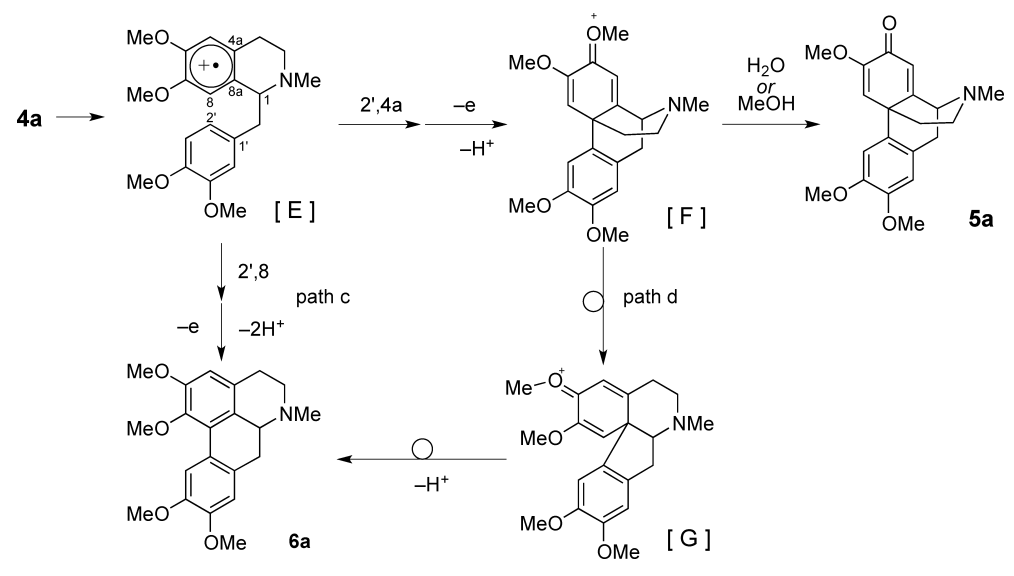

Chart 5. Possible Reaction Formation Mechanism for $\mathbf{5 a}$ and $\mathbf{6 a}$

yield (entries 7, 8). Products from $\mathbf{8 q}$ and $\mathbf{8 r}$ are possible analogs of gryndelic acid derivatives, which were isolated from Grindelia nana, and the ethanol extract demonstrated in vitro inhibitory effects on human immunodeficiency virus (HIV)-1 reverse transcriptase. ${ }^{169-171)}$

\section{The Use of Oxometalate Catalyst together with PNIPAAm in the Development of New Oxidation Sys- tems}

Oxometalate catalysts have great potential to provide green catalytic oxidation systems that use hydrogen peroxide or oxygen gas as primary oxidant, which is readily available and produces water as the sole by-product. ${ }^{1-32)}$ Although many known and new oxometalate catalysts are being applied to a wide variety of oxidation reactions, there is still a strong requirement for development of more efficient and safe oxidation methods in view of fine chemical and pharmaceutical syntheses.
The immobilization of catalysts on solid supports offers a number of important advantages over their homogeneous counterparts. ${ }^{172-181)}$ For example, their separation of catalyst from reaction products is easy and their potentiality for consecutive recycling steps is accessible for green chemical process. In addition, immobilization on solid phase often causes stabilization of sensitive catalyst. Despite these advantages, solid phase catalyst, in which the reaction drives on surface, shows lower reactivity due to weak affinity between substrate and catalyst under heterogeneous conditions. Because of this significant disadvantage, solid phase reaction system diminishes its synthetic utility in many cases. In recent years, much attention is focused on creation of new reaction systems that exploit multi-functionalized materials via thermomorphic effect. The use of biphasic reaction system employing ionic liquids or fluorous solvents to hold efficient catalytic activity is recognized as a potential strategy. ${ }^{182-206)}$ The main concept of these methods is to utilize the thermomorphic phase behavior 
Table 8. Syntheses of Morphinandienones

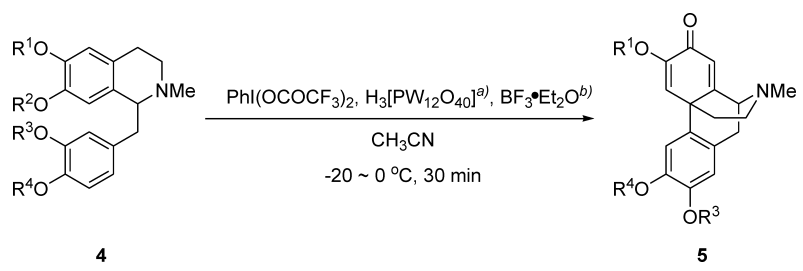

\begin{tabular}{|c|c|c|c|c|c|c|}
\hline Substrate & $\mathrm{OR}^{1}$ & $\mathrm{OR}^{2}$ & $\mathrm{OR}^{3}$ & $\mathrm{OR}^{4}$ & Product & Yield $\left.(\%)^{c}\right)$ \\
\hline $4 a$ & $\mathrm{OMe}$ & $\mathrm{OMe}$ & $\mathrm{OMe}$ & $\mathrm{OMe}$ & $\begin{array}{l}\text { 5a ( } O \text {-methylflavi- } \\
\text { nantine) }\end{array}$ & 90 \\
\hline $4 b$ & $\mathrm{OMe}$ & $\mathrm{OMe}$ & \multicolumn{2}{|c|}{$\mathrm{OCH}_{2} \mathrm{O}$} & $\mathbf{5 b}$ (amurine) & 90 \\
\hline $4 c$ & $\mathrm{OBn}$ & $\mathrm{OMe}$ & $\mathrm{OMe}$ & $\mathrm{OMe}$ & $5 \mathbf{c}$ & 76 \\
\hline $4 d$ & $\mathrm{OMe}$ & $\mathrm{OBn}$ & $\mathrm{OMe}$ & $\mathrm{OMe}$ & $5 a$ & 85 \\
\hline $4 e$ & $\mathrm{OMe}$ & $\mathrm{OMe}$ & OBn & $\mathrm{OMe}$ & $\begin{array}{l}\text { 5e (O-benzylpalli- } \\
\text { dine) }\end{array}$ & 79 \\
\hline $4 f$ & $\mathrm{OMe}$ & $\mathrm{OMe}$ & $\mathrm{OMe}$ & $\mathrm{OBn}$ & $\begin{array}{l}\text { 5f }(O \text {-benzylflavi- } \\
\text { natine })\end{array}$ & 82 \\
\hline
\end{tabular}

a) $25 \mathrm{mg} / \mathrm{mL}$. b) 5 eq. c) Yield of isolated products.

Table 9. Oxidative Coupling Reaction of $N$-Trifluoroacetylnorlaudanosine (4g)

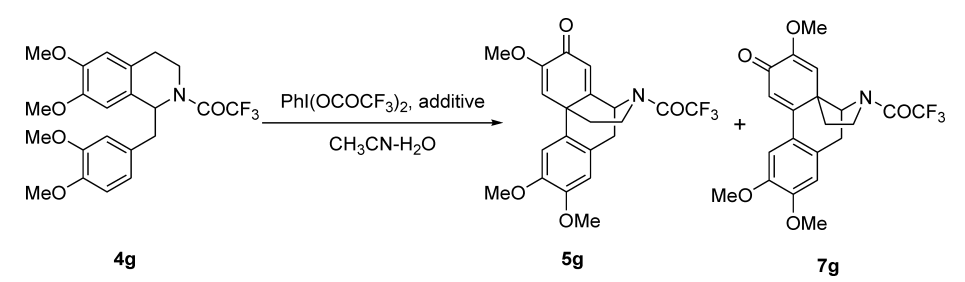

\begin{tabular}{|c|c|c|c|c|c|c|}
\hline Entry & Additive & $\mathrm{H}_{2} \mathrm{O}$ & Temperature & Time & $5 \mathbf{g}(\%)^{a)}$ & $7 \mathrm{~g}(\%)^{a)}$ \\
\hline 1 & $\mathrm{BF}_{3} \cdot \mathrm{Et}_{2} \mathrm{O}^{b)}$ & None & $-40-0^{\circ} \mathrm{C}$ & $30 \mathrm{~min}$ & 0 & 90 \\
\hline 2 & $\mathrm{H}_{3}\left[\mathrm{PW}_{12} \mathrm{O}_{40}\right]^{c)}$ & None & $-20-0^{\circ} \mathrm{C}$ & $30 \mathrm{~min}$ & 63 & 32 \\
\hline 3 & $\mathrm{H}_{3}\left[\mathrm{PW}_{12} \mathrm{O}_{40}\right]^{c)}$ & $2.5 \%$ & $-20-0^{\circ} \mathrm{C}$ & $1 \mathrm{~h}$ & 84 & 9 \\
\hline 4 & $\mathrm{H}_{3}\left[\mathrm{PW}_{12} \mathrm{O}_{40}\right]^{c)}\left(\mathrm{CF}_{3} \mathrm{CO}\right)_{2} \mathrm{O}^{d)}$ & None & $-20-0^{\circ} \mathrm{C}$ & $30 \mathrm{~min}$ & 0 & 90 \\
\hline 5 & $\mathrm{BF}_{3} \cdot \mathrm{Et}_{2} \mathrm{O}^{b)}$ & $2.5 \%$ & $0^{\circ} \mathrm{C}-\mathrm{rt}$ & $3 \mathrm{~h}$ & 43 & 13 \\
\hline
\end{tabular}

a) Yield of isolated products. b) 2 eq. c) $c a .30 \mathrm{~mol} \%$. d) 4 eq.

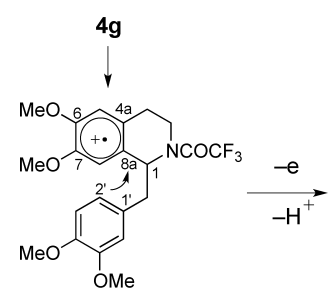

$[\mathrm{H}]$

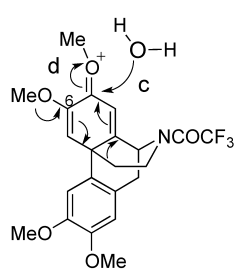

[l]
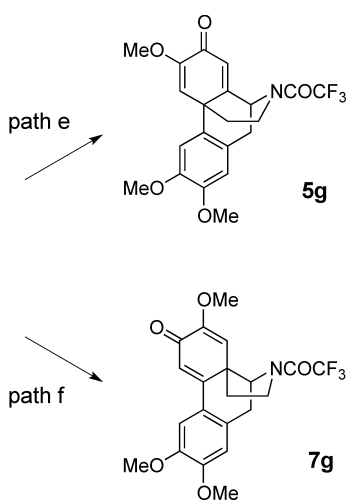

Chart 6. Possible Reaction Formation Mechanism for 5g and $\mathbf{7 g}$

and distribution of catalysts in the solvent for efficient recycling without loss of catalytic activity. The popularity of these systems has significantly increased over the last decade. In this work, we focused on exploitation of multi-functionalized polymer support for immobilization of oxometalate catalysts to achieve development of novel oxidation systems in organic synthesis.
3.1. Thermomorphic Property of Polyoxometalate Immobilized on PNIPAAm Poly( $N$-isopropylacrylamide) (PNIPAAm)-based polymers, the best-known multi-functionalized polymer, intrinsically show characteristic temperatureresponsive intelligence, and have been applied to various fields such as drug-delivery systems, column packing materials, and cell culture substrates by using external temperature changes 
Table 10. Synthesis of Morphinandienones (5) and Neospirinedienones (7)

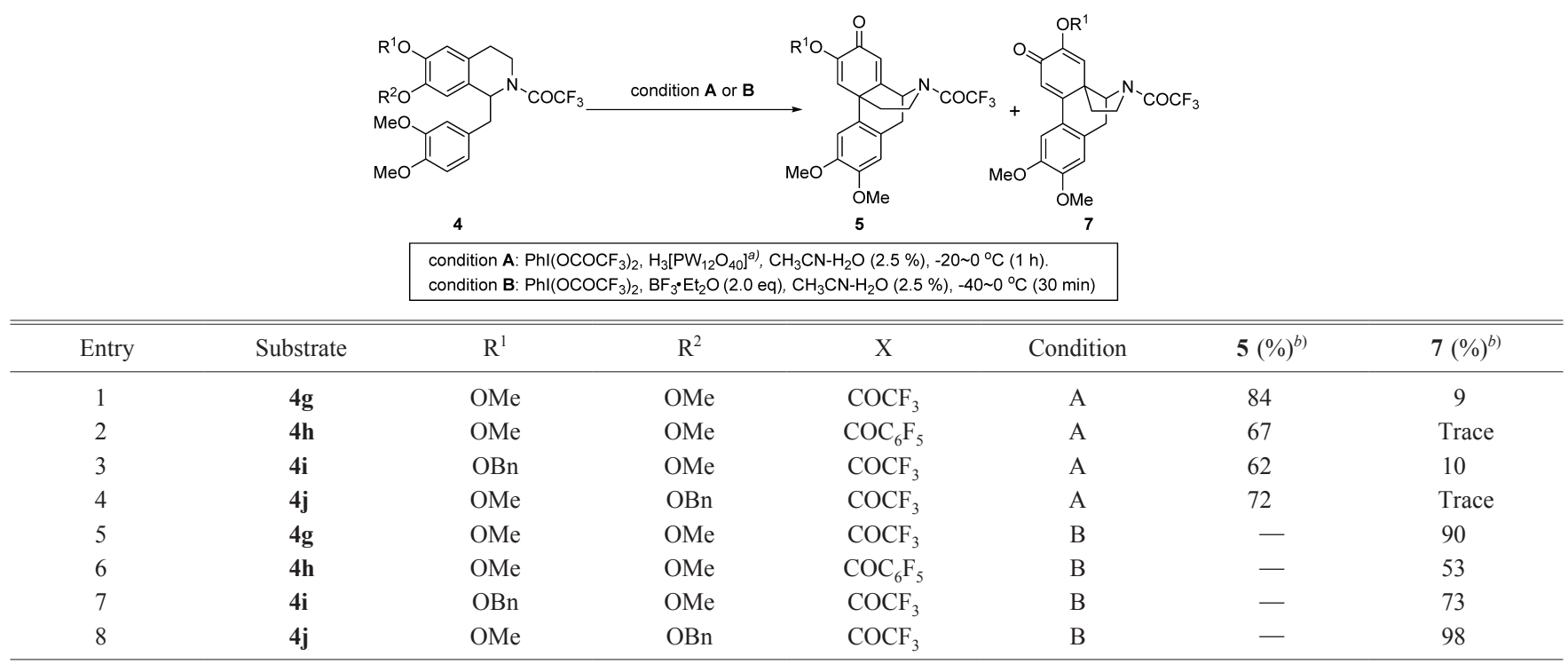

a) $25 \mathrm{mg} / \mathrm{mL}(c a .30 \mathrm{~mol} \%)$. b) Yield of isolated product.

Table 11. Intramolecular Oxidative Cyclization of $\mathbf{8 a}$

\begin{tabular}{|c|c|c|c|c|c|}
\hline \multirow{2}{*}{ Entry } & \multirow{2}{*}{ Reagents and solvents } & \multirow{2}{*}{ Temperature } & \multirow{2}{*}{ Time } & \multicolumn{2}{|c|}{ Yield $(\%)^{a)}$} \\
\hline & & & & 9a & 10a \\
\hline $1^{b)}$ & $\begin{array}{l}\mathrm{Tl}_{2} \mathrm{O}_{3}, \mathrm{BF}_{3} \cdot \mathrm{Et}_{2} \mathrm{O}, \mathrm{TFA}, \mathrm{TFAA} \\
\quad \mathrm{CH}_{2} \mathrm{Cl}_{2}\end{array}$ & $-20^{\circ} \mathrm{C}$ & $1 \mathrm{~min}$ & 38 & 19 \\
\hline $2^{b)}$ & $\mathrm{VOF}_{3}$, TFA, TFAA, $\mathrm{CH}_{2} \mathrm{Cl}_{2}$ & $-20^{\circ} \mathrm{C}$ & $2.5 \mathrm{~h}$ & - & - \\
\hline 3 & $\mathrm{PhI}\left(\mathrm{OCOCF}_{3}\right)_{2}, \mathrm{HFIP}$ & $0^{\circ} \mathrm{C}$ & $5 \mathrm{~min}$ & 15 & 8 \\
\hline 4 & $\begin{array}{l}\mathrm{PhI}\left(\mathrm{OCOCF}_{3}\right)_{2}, \mathrm{BF}_{3} \cdot \mathrm{Et}_{2} \mathrm{O} \\
\quad \mathrm{CH}_{2} \mathrm{Cl}_{2}\end{array}$ & $-40^{\circ} \mathrm{C}$ & $10 \mathrm{~min}$ & 11 & 9 \\
\hline 5 & $\begin{array}{l}\mathrm{PhI}\left(\mathrm{OCOCF}_{3}\right)_{2}, \mathrm{BF}_{3} \cdot \mathrm{Et}_{2} \mathrm{O} \\
\left.\quad \mathrm{CH}_{3} \mathrm{CN}^{c}\right)\end{array}$ & $0^{\circ} \mathrm{C}-\mathrm{rt}$ & $1 \mathrm{~h}$ & 40 & 12 \\
\hline 6 & $\begin{array}{l}\mathrm{PhI}\left(\mathrm{OCOCF}_{3}\right)_{2}, \mathrm{CF}_{3} \mathrm{SO}_{3} \mathrm{H} \\
\quad \mathrm{CH}_{3} \mathrm{CN}^{c)}\end{array}$ & $0^{\circ} \mathrm{C}-\mathrm{rt}$ & $1 \mathrm{~h}$ & 41 & 9 \\
\hline 7 & $\begin{array}{l}\mathrm{PhI}\left(\mathrm{OCOCF}_{3}\right)_{2}, \mathrm{H}_{4}\left[\mathrm{PMo}_{12} \mathrm{O}_{40}\right],{ }^{d)} \\
\quad \mathrm{CH}_{3} \mathrm{CN}^{c)}\end{array}$ & $0^{\circ} \mathrm{C}-\mathrm{rt}$ & $2 \mathrm{~h}$ & 52 & 13 \\
\hline 8 & $\begin{array}{l}\mathrm{PhI}\left(\mathrm{OCOCF}_{3}\right)_{2}, \mathrm{H}_{4}\left[\mathrm{PW}_{12} \mathrm{O}_{40}\right],{ }^{d)} \\
\quad \mathrm{CH}_{3} \mathrm{CN}^{c)}\end{array}$ & $0^{\circ} \mathrm{C}-\mathrm{rt}$ & $1.5 \mathrm{~h}$ & 61 & 11 \\
\hline 9 & $\begin{array}{l}\mathrm{PhI}\left(\mathrm{OCOCF}_{3}\right)_{2}, \mathrm{H}_{4}\left[\mathrm{SiMo}_{12} \mathrm{O}_{40}\right],{ }^{d)} \\
\quad \mathrm{CH}_{3} \mathrm{CN}^{c)}\end{array}$ & $0^{\circ} \mathrm{C}-\mathrm{rt}$ & $1 \mathrm{~h}$ & 55 & 11 \\
\hline 10 & $\begin{array}{l}\mathrm{PhI}\left(\mathrm{OCOCF}_{3}\right)_{2}, \mathrm{H}_{4}\left[\mathrm{SiW}_{12} \mathrm{O}_{40}\right],{ }^{d)} \\
\quad \mathrm{CH}_{3} \mathrm{CN}^{c)}\end{array}$ & $0^{\circ} \mathrm{C}-\mathrm{rt}$ & $0.5 \mathrm{~h}$ & 69 & 11 \\
\hline
\end{tabular}

a) Yield of isolated product. b) See ref. 165. c) wet $\mathrm{CH}_{3} \mathrm{CN}: \mathrm{CH}_{3} \mathrm{CN}$ containing $2.5 \%$ water. $d$ ) $c a .0 .06 \mathrm{moleq}$.

(Fig. 3). ${ }^{207-209)}$ PNIPAAm polymers undergo thermally reversible changes between water soluble and insoluble states across a lower critical solution temperature (LCST) of $30-40^{\circ} \mathrm{C} .^{208)}$ Thus the polymer chains of PNIPAAm are hydrated below the LCST and dehydrated with aggregation above LCST. Several efficient applications of soluble PNIPAAm-supported catalyst to biphasic system have already been reported by Bergbreiter's group; the advantages of these applications are highlighted in their recent reviews. ${ }^{210-213)}$ However, the applications of PNIPAAm-based copolymer catalyst in aqueous medium toward clean and safe oxidation systems are still limited. This work focuses much attention on the use of thermoregulated hydrophobic species formed by PNIPAAm as novel organic reaction medium in water. ${ }^{214-220)}$

Previously, our group found that an assembled complex of non-cross-linked PNIPAAm copolymer ligands and inorganic salts affords insoluble solids in water and possesses functions as a triphase catalyst. ${ }^{221-224)}$ To design a new oxometalate catalyzed oxidation system based on thermomorphic property of PNIPAAm, a dye-labeled catalyst $\mathbf{1 1 b}$ comprising a 
Table 12. Synthesis of Spirodienone Lactones
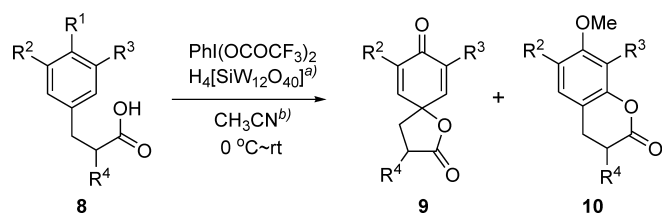

\begin{tabular}{|c|c|c|c|c|c|c|c|}
\hline \multirow{2}{*}{ Entry } & \multirow{2}{*}{ Substrate } & \multirow{2}{*}{$\mathrm{R}^{1}$} & \multirow{2}{*}{$\mathrm{R}^{2}$} & \multirow{2}{*}{$\mathrm{R}^{3}$} & \multirow{2}{*}{$\mathrm{R}^{4}$} & \multicolumn{2}{|c|}{ Yield $(\%)^{c)}$} \\
\hline & & & & & & 9 & 10 \\
\hline 1 & $8 b$ & $\mathrm{OMe}$ & $\mathrm{H}$ & $\mathrm{H}$ & $\mathrm{H}$ & 84 & - \\
\hline 2 & $8 c$ & $\mathrm{OMe}$ & $\mathrm{Me}$ & $\mathrm{H}$ & $\mathrm{H}$ & 76 & - \\
\hline 3 & $8 d$ & $\mathrm{OMe}$ & $\mathrm{OMe}$ & $\mathrm{H}$ & $\mathrm{Me}$ & 79 & 8 \\
\hline 4 & $8 e$ & $\mathrm{OMe}$ & $\mathrm{OMe}$ & $\mathrm{H}$ & $\mathrm{Bn}$ & 76 & 5 \\
\hline 5 & $8 f$ & $\mathrm{OMe}$ & $\mathrm{OBn}$ & $\mathrm{H}$ & $\mathrm{H}$ & 60 & 7 \\
\hline 6 & $8 g$ & OBn & $\mathrm{OMe}$ & $\mathrm{H}$ & $\mathrm{H}$ & 69 & 8 \\
\hline 7 & $8 \mathrm{~h}$ & $\mathrm{OBn}$ & $\mathrm{OBn}$ & $\mathrm{H}$ & $\mathrm{H}$ & 79 & 9 \\
\hline 8 & $8 \mathbf{i}$ & $\mathrm{OMe}$ & $\mathrm{OMe}$ & $\mathrm{OMe}$ & $\mathrm{H}$ & 63 & - \\
\hline 9 & $8 \mathbf{j}$ & & 3-(4-Met & alen-1-y & & 96 & - \\
\hline
\end{tabular}

a) ca. 0.06 moleq. b) wet $\mathrm{CH}_{3} \mathrm{CN}: \mathrm{CH}_{3} \mathrm{CN}$ containing $2.5 \%$ water. $c$ ) Yield of isolated product.

Table 13. Synthesis of Spirodienone Ethers

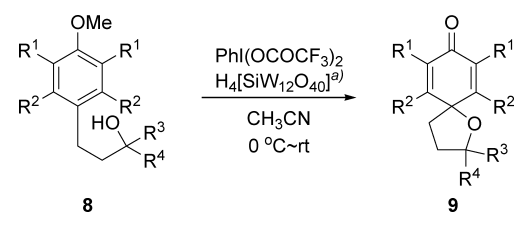

\begin{tabular}{|c|c|c|c|c|c|c|c|}
\hline Entry & Substrate & $\mathrm{R}^{1}$ & $\mathrm{R}^{2}$ & $\mathrm{R}^{3}$ & $\mathrm{R}^{4}$ & Time & Yield $(\%)^{b)}$ \\
\hline 1 & $8 k$ & $\mathrm{Me}$ & $\mathrm{H}$ & $\mathrm{H}$ & $\mathrm{H}$ & $30 \mathrm{~min}$ & 50 \\
\hline $2^{c)}$ & 81 & $\mathrm{H}$ & $\mathrm{Me}$ & $\mathrm{H}$ & $\mathrm{H}$ & $30 \mathrm{~min}$ & 79 \\
\hline $3^{c)}$ & $8 m$ & $\mathrm{H}$ & $\mathrm{Me}$ & $\mathrm{Me}$ & $\mathrm{H}$ & $30 \mathrm{~min}$ & 83 \\
\hline $4^{(d)}$ & $8 n$ & $\mathrm{H}$ & $\mathrm{Me}$ & $\mathrm{Me}$ & $\mathrm{Me}$ & $2 \mathrm{~h}$ & 68 \\
\hline $5^{d)}$ & 80 & $\mathrm{OMe}$ & $\mathrm{H}$ & $\mathrm{H}$ & $\mathrm{H}$ & $6 \mathrm{~min}$ & 85 \\
\hline $6^{d)}$ & $8 p$ & $\mathrm{H}$ & $\mathrm{OMe}$ & $\mathrm{H}$ & $\mathrm{H}$ & $1.5 \mathrm{~h}$ & 63 \\
\hline $7^{d)}$ & $8 q$ & $\mathrm{H}$ & $\mathrm{Me}$ & $\mathrm{CH}_{2} \mathrm{CH}_{2} \mathrm{OH}$ & $\mathrm{Me}$ & $30 \mathrm{~min}$ & 52 \\
\hline $8^{d)}$ & $8 r$ & $\mathrm{H}$ & $\mathrm{Me}$ & $\mathrm{CH}_{2} \mathrm{CO}_{2} \mathrm{Et}$ & $\mathrm{Me}$ & $1 \mathrm{~h}$ & 39 \\
\hline
\end{tabular}

a) ca. 0.06 mol eq. b) Yield of isolated product. c) wet $\mathrm{CH}_{3} \mathrm{CN}$ : $\mathrm{CH}_{3} \mathrm{CN}$ containing $2.5 \%$ water. d) wet $\mathrm{CH}_{3} \mathrm{CN}$ : $\mathrm{CH}_{3} \mathrm{CN}$ containing $5 \%$ water.

phosphotungstate anion, a PNIPAAm polymer chain, and a Disperse Red moiety was synthesized (Chart 7). ${ }^{224)}$ Interestingly, this model catalyst $\mathbf{1 1 b}$ could cause drastic mode transfer at several temperatures in aqueous medium; when 11b is used together with water and the organic substrates it is insoluble in both phase at room temperature. On heating the organic substrates gradually soak into $\mathbf{1 1 b}$ and the absorption completes at around $60^{\circ} \mathrm{C}$, wheras excess heating to $>70^{\circ} \mathrm{C}$ tends to induce generation of emulsion species (Fig. 4). Since the colloidal aggregation, such as emulsions formed by amphiphilic molecules in water, could be an effective reaction medium for several oxometalate catalyzed oxidations, ${ }^{225-228)}$ the use of specific hydrophobic species formed by PNIPAAm as novel organic reaction medium in water is expected to open up a facile alternative to access the creation of new recyclable catalytic systems.

3.2. Thermoregulated Micelle-Emulsion System A micellar-type system utilizing switchable catalyst based on the characteristic temperature responsive intelligence of 11a exerted high performances for catalyst recycling with efficient

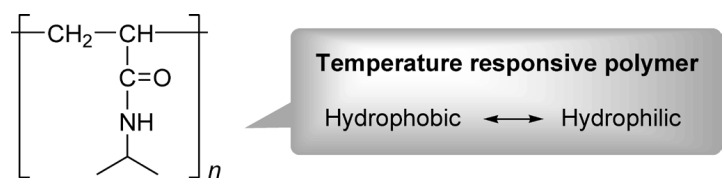

Fig. 3. Poly- $N$-isopropylacrylamide (PNIPAAm)

activity as summarized in Fig. $5 .^{216)}$ In phosphotungstate catalyzed hydrogen peroxide oxidation of 1-phenyl-1-propanol in water, thermoregulated formation of a stable emulsion was detected at $90^{\circ} \mathrm{C}$ and higher reactivity was observed (Table 14). The catalyst was precipitated on cooling and cleanly separated from the reaction mixture after addition of diethyl ether. The recovered 11a was reused for consecutive reaction without significant loss of catalytic efficacy. Although the reactivity of 11a on homogeneous system was also examined using various organic solvents such as $t-\mathrm{BuOH}$ and $\mathrm{CH}_{3} \mathrm{CN}$, no significant activity was observed in each case and excess amounts of organic solvents were required for the extractive 


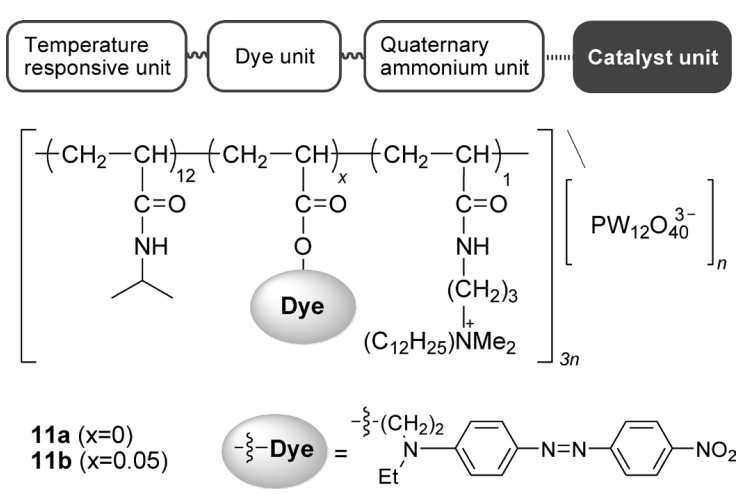

Chart 7. Design of Thermomorphic Polymer-Supported Polyoxometalate $\mathbf{1 1}$
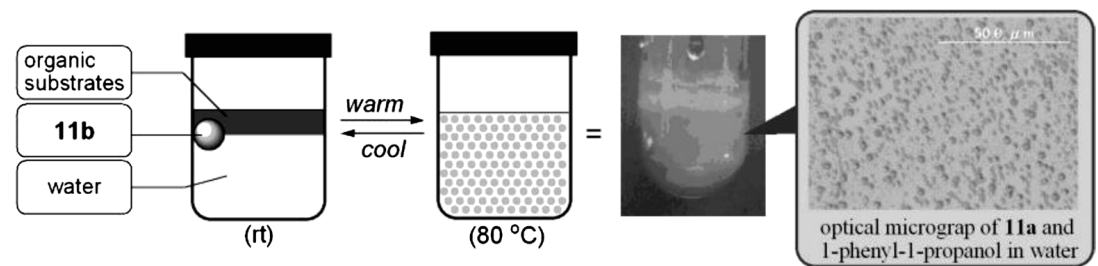

Fig. 4. Generation of Emulsion Species by 11

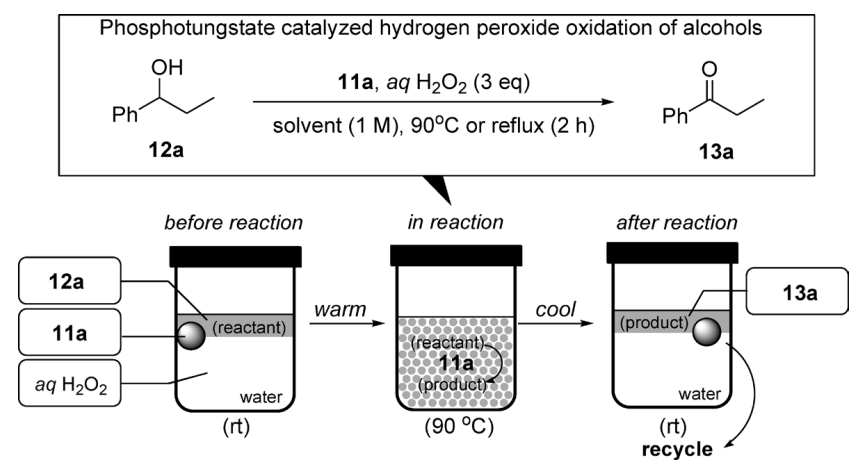

Fig. 5. Simplified Representation of Emulsion Type Thermomorphic Catalysis System Utilizing 11

work-up process. It is noteworthy that this catalytic system based on micellar-type aggregates in water is more effective than homogeneous systems in both catalytic activity and recyclability. In addition, the oxidation using this condition works well for a range of secondary and primary alcohols to yield the corresponding ketones and carboxylic acids, respectively (Table 15).

3.3. Thermoregulated Gel-Phase System The use of the temporally formed specific hydrophobic PNIPAAm gel phase holding the flexible solid state as specific organic reaction medium provided also efficient thermomorphic catalysis systems in water (Fig. 6). ${ }^{220)}$ In 11a-catalyzed oxidative cyclization with hydrogen peroxide in water, absorption of organic materials in the catalyst phase was similarly detected at $60^{\circ} \mathrm{C}$, and higher reactivity owing to hydrophobic effect was observed. The organic materials retained in gel were released by cooling the reaction mixture and the organic/aqueous/ solid phases were cleanly separated after addition of diethyl ether. The recovered 11a could be used for subsequent reactions without any significant loss of catalytic efficacy. Comparison of reactivities on oxidation with conventional tungsten
Table 14. Oxidation of 1-Phenyl-1-propanol (12a) Catalyzed by 11a

\begin{tabular}{cllc}
\hline \hline Entry & \multicolumn{1}{c}{ Solvent } & Conditions & Yield (\%) \\
\hline $1^{b)}$ & $\mathrm{H}_{2} \mathrm{O}$ & Emulsion & 92 \\
$2^{b)}$ & $\mathrm{H}_{2} \mathrm{O}$ & Emulsion & 92 (2nd use) \\
$3^{b)}$ & $\mathrm{H}_{2} \mathrm{O}$ & Emulsion & 90 (3rd use) \\
$4^{c)}$ & $t-\mathrm{BuOH}$ & Homogeneous & 35 \\
$5^{c)}$ & $\mathrm{CH}_{3} \mathrm{CN}$ & Homogeneous & 34 \\
\hline
\end{tabular}

a) Yield of isolated product. b) Condition: 11a $\left.(0.1 \mathrm{~mol} \%), 90^{\circ} \mathrm{C} . c\right)$ Condition 11a $(0.5 \mathrm{~mol} \%)$, reflux. 


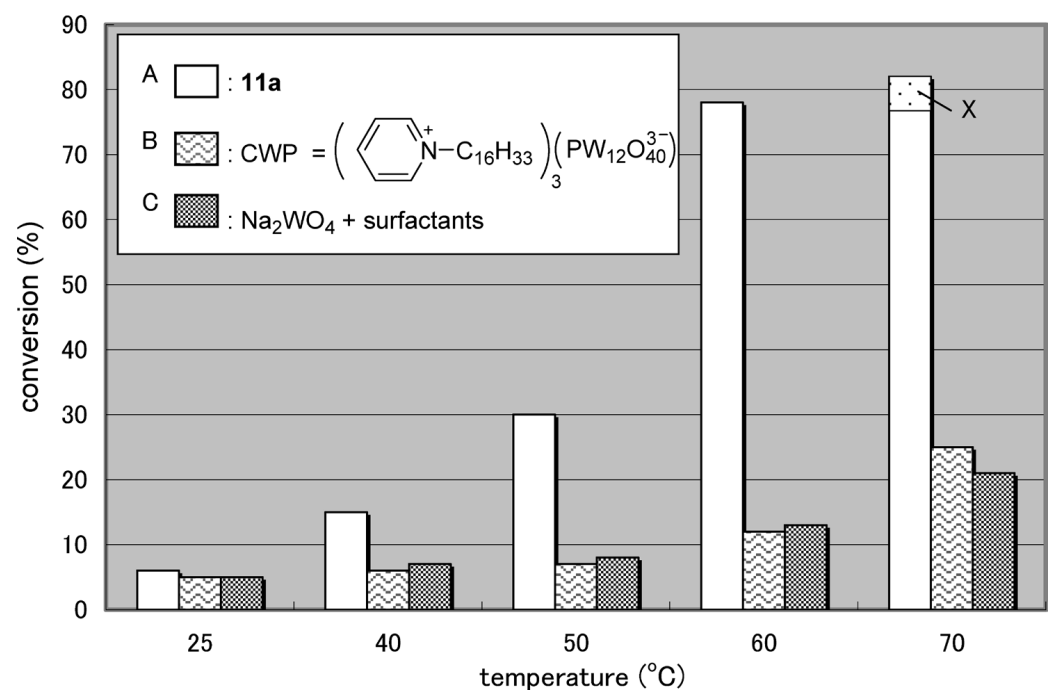

Fig. 7. Oxidative Cyclization of 14a in the Presence of Various Tungstate Catalyst Systems

Conditions: A) 11a (0.4 mol\%), 10\% aq. $\mathrm{H}_{2} \mathrm{O}_{2}, 6 \mathrm{~h}$; B) CWP $(0.4 \mathrm{~mol} \%), 10 \%$ aq. $\mathrm{H}_{2} \mathrm{O}_{2}, 6 \mathrm{~h} ; \mathrm{C}^{2} \mathrm{Na}_{2} \mathrm{WO}_{4} \cdot 2 \mathrm{H}_{2} \mathrm{O}(4.8 \mathrm{~mol} \%),\left[\mathrm{CH}_{3}\left(n-\mathrm{C}_{8} \mathrm{H}_{17}\right)_{3} \mathrm{~N}\right] \mathrm{HSO}_{4}, \mathrm{NH}_{2} \mathrm{CH}_{2} \mathrm{PO}_{3} \mathrm{H}, 10 \%$ aq. $\mathrm{H}_{2} \mathrm{O}_{2}, 6 \mathrm{~h}$ (=undesired product).

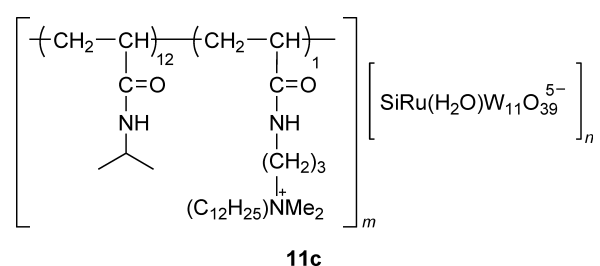

Chart 8. Polymer-Supported Ruthenium Substituting Polyoxometalate 11c

polymer was utilized to immobilize oxometalates such as perruthenate $\left(\mathrm{RuO}_{4}^{-}\right)($Chart 10). Similar to 11, the absorption of organic materials in the cross-linked PNIPAAm was detected by heating the reaction mixture where the oil containing polymer gel is more rigid in comparison with polymer complex $\mathbf{1 1}$ and could retain a gel form at $90^{\circ} \mathrm{C}$ (Fig. 8). In 20-catalyzed aerobic oxidation of primary alcohols, high activity was exerted and the corresponding carboxylic acids were obtained in good yields (Tables 17, 18). The catalyst was easily separated from the reaction mixture after cooling and the recovered
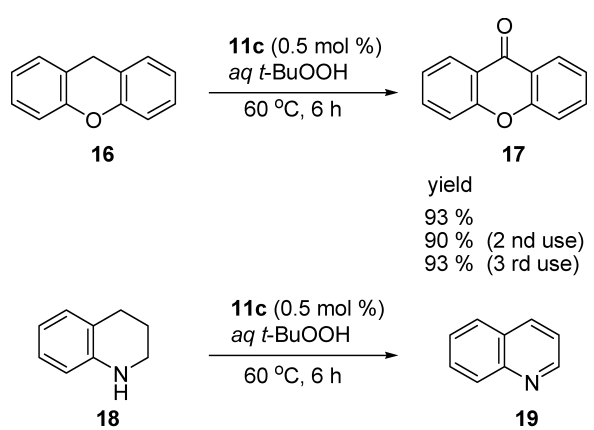

$\underset{\substack{11 \mathrm{c}(0.5 \mathrm{~mol} \%) \\ \text { aq } t \text {-BuOOH }}}{\stackrel{{ }^{\circ} \mathrm{C}, 6 \mathrm{~h}}{\longrightarrow}}$

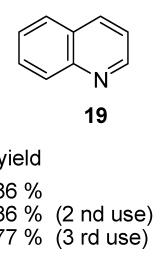

Chart 9. Oxidation of Xanthene and Tetrahydroquinoline Catalyzed by 11c

catalyst could also be used for consecutive reactions without any significant loss of catalytic efficacy. The re-usability of this catalyst for ten cycles was still excellent. In addition, this

Table 15. Oxidation of Primary and Secondary Alcohols Catalyzed by 11a ${ }^{a}$

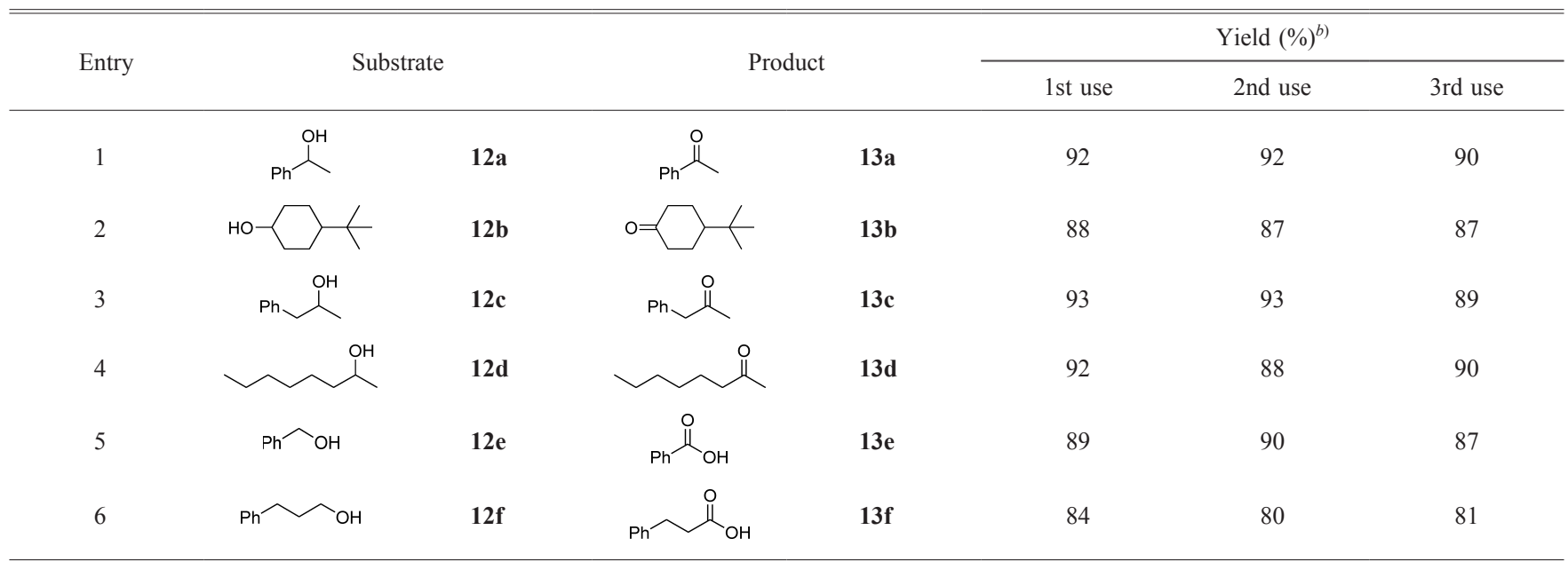

a) Condition: 11a $(0.1-0.4 \mathrm{~mol} \%), 10 \% \mathrm{H}_{2} \mathrm{O}_{2}$ aq. $\left.(1.5-3 \mathrm{eq}), 90^{\circ} \mathrm{C}(6 \mathrm{~h}) . b\right)$ Yield of isolated products. 
Table 16. Oxidative Cyclization Catalyzed by $\mathbf{1 1} \mathbf{a}^{a}$

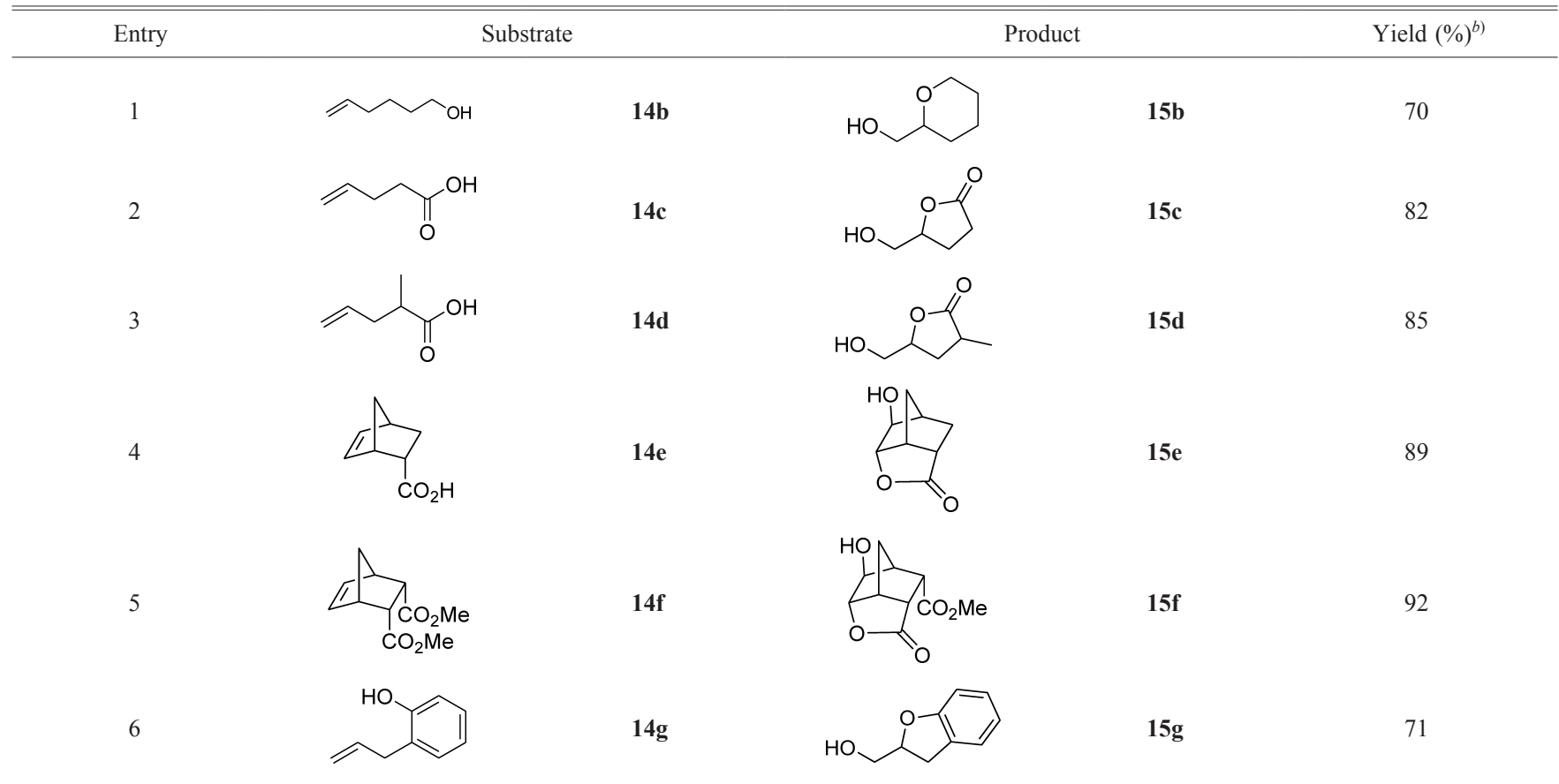

a) Condition: 11a $(0.4 \mathrm{~mol} \%), 10 \% \mathrm{H}_{2} \mathrm{O}_{2}$ aq. $\left.2-3 \mathrm{eq}\right), 90^{\circ} \mathrm{C}(6 \mathrm{~h})$. b) Yield of isolated products.

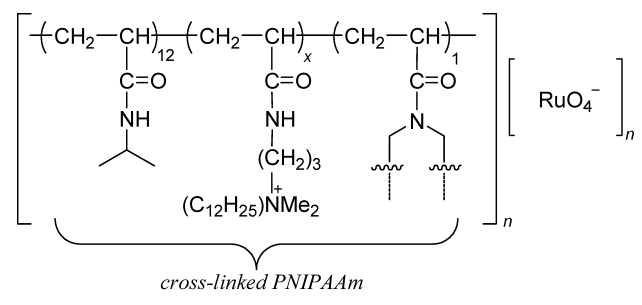

20

Chart 10. Cross-Linked PNIPAAm-Supported Oxometalate 20

system is also applicable for oxidative coupling reaction of naphthols with molecular oxygen in water (Table 19). Again, this thermomorphic system brought remarkable acceleration of reactivity and ease of catalyst recycling using the catalyst intelligence.

In this context, polyethylene glycol (PEG)-containing PNIPAAm immobilized perruthenate $\mathbf{2 5 b}$ was successfully used in aerobic oxidation of alcohols in organic medium (Chart 11, Table 20). ${ }^{219)}$ PEG-PNIPAAm Ru-catalyst 25b exhibited efficient catalytic activity in oxidation of 4-methylbenzyl alcohol in organic medium, although PEG-free-PNIPAAm $\mathrm{Ru}$ catalyst 25a diminished the catalytic activity (entries 1,2 ). Investigation of the effects of water presence in the oxidation process indicated that hydrophilic PEG component on $\mathbf{2 5 b}$ plays important roles in the removal of water generated during the course of the oxidation from the catalytic site in an identical phase among a hydrophobic PNIPAAm gel environment at high temperature. In addition, the holding water would be released after cooling due to loss of hydrophobicity on the PNIPAAm chain. The catalyst could be recovered by simple filtration and reused without significant loss of activity. In addition, oxidation using this condition works well for a range of primary alcohols to yield the corresponding aldehydes (Table 21).
Table 17. Aerobic Oxidation of 4-Methylbenzyl Alcohol Catalyzed by 20

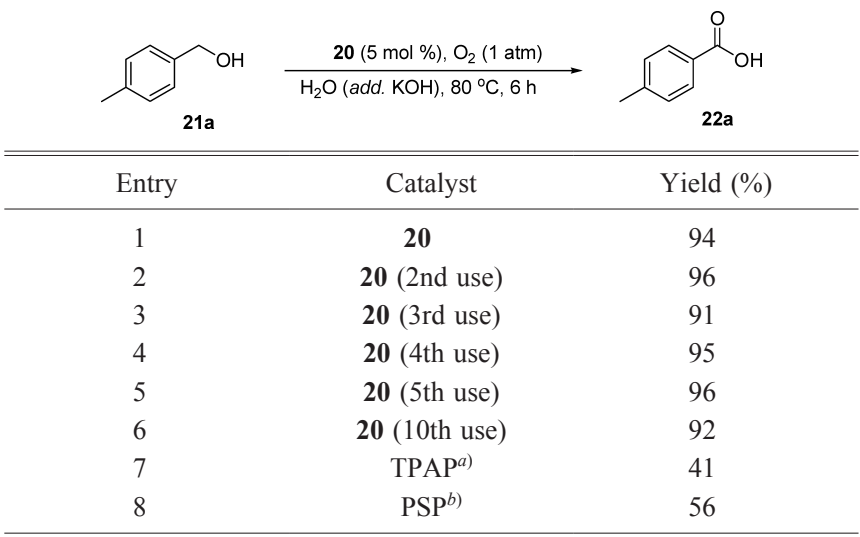

a) TPAP $\left(n-\mathrm{Pr}_{4} \mathrm{~N}^{+} \mathrm{RuO}_{4}^{-}\right)$. b) PSP (polymer supported perruthenate: amberlyst 26 and $\mathrm{RuO}_{4}^{-}$).

\section{Conclusion}

In this review we described the novel use of oxometalate and polyoxometalate catalysts in the design of new oxidation systems in organic synthesis. We have successfully developed an efficient method to generate cation radical species by the use of acidic oxometalate catalyst, HPA, in hypervalent iodine-mediated oxidations. This method brought a facile biaryl synthesis and new spirodienone syntheses in aromatic oxidation chemistry. Moreover, this method opens up a facile synthetic route to morphinandienone alkaloids. On the other hand, we also successfully developed effective methods to use oxometalate catalyst together with PNIPAAm as the attractive functionalized solid-phase catalyst for several oxidation systems in aqueous media. Thanks to the characteristic temperature-responsive intelligence of PNIPAAm, this reaction system brought remarkable acceleration of reactivity and 


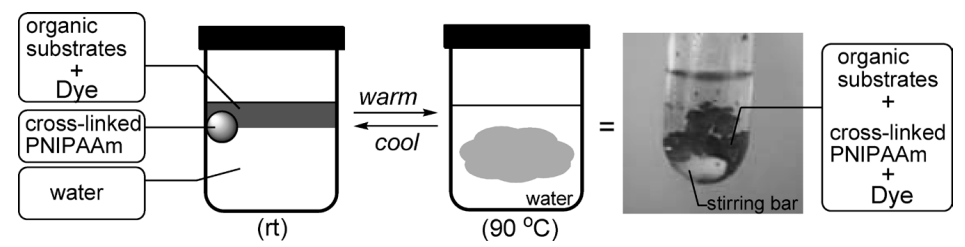

Fig. 8. Absorption of Organic Substrate into Crosslinked PNIPAAm

Table 18. Aerobic Oxidation of Primary Alcohols Catalyzed by $\mathbf{2 0}^{a)}$

Entry Substrate

a) Condition: 20 ( $5 \mathrm{~mol} \%), \mathrm{O}_{2}(1 \mathrm{~atm}), \mathrm{H}_{2} \mathrm{O}$ (add. $\left.\mathrm{KOH}\right), 80^{\circ} \mathrm{C}(6-12 \mathrm{~h})$. b) Yield of isolated products.

Table 19. Oxidative Coupling Reaction Catalyzed by $\mathbf{2 0}^{a)}$

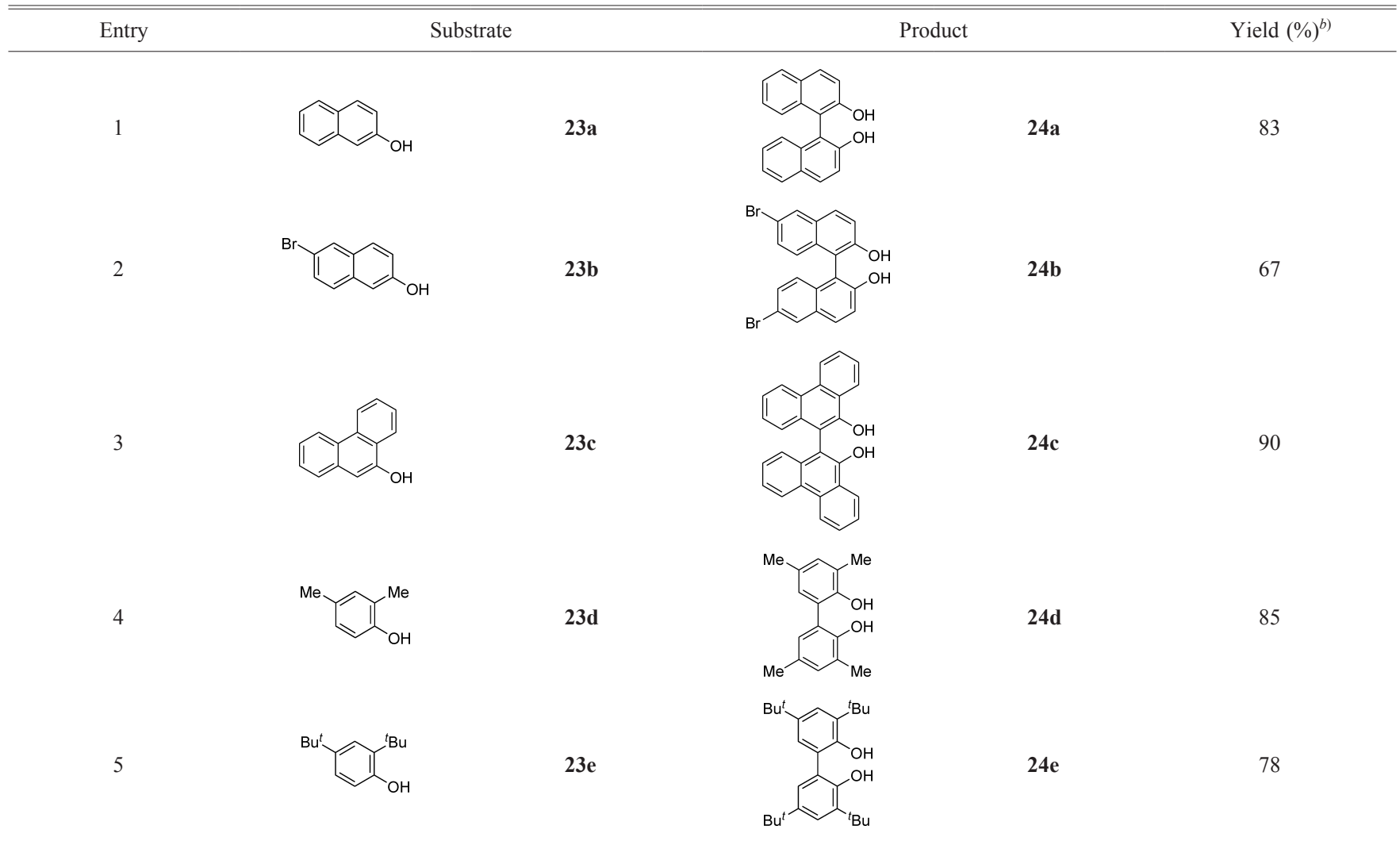




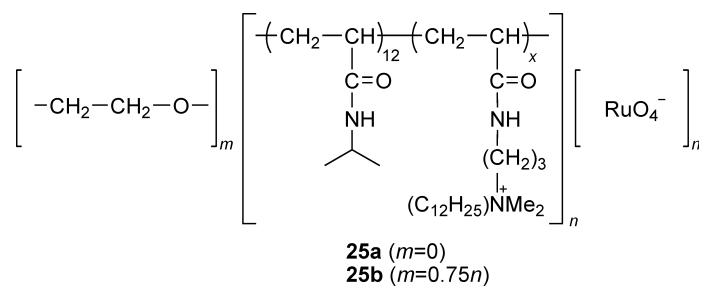

Chart 11. PEG-Containing PNIPAAm Supported Oxometalate
Table 20. Aerobic Oxidation of 4-Methylbenzyl Alcohol Catalyzed by 25

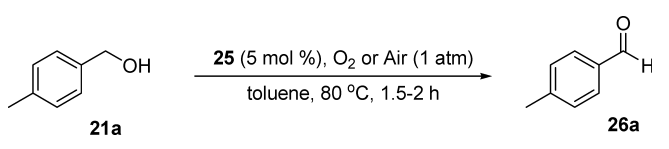

\begin{tabular}{cccc}
\hline \hline Entry & Catalyst & $\mathrm{O}_{2}$ or air & Yield (\%) \\
\hline 1 & 25a & $\mathrm{O}_{2}$ & 44 \\
2 & 25b & $\mathrm{O}_{2}$ & 91 \\
3 & 25b (2nd use) & $\mathrm{O}_{2}$ & 84 \\
4 & 25b (3rd use) & $\mathrm{O}_{2}$ & 84 \\
5 & 25b (4th use) & $\mathrm{O}_{2}$ & 93 \\
6 & 25b (5th use) & $\mathrm{O}_{2}$ & 86 \\
7 & 25b & Air & 90 \\
\hline
\end{tabular}

Table 21. Aerobic Oxidation of Primary Alcohols Catalyzed by $\mathbf{2 5 \mathbf { b } ^ { a ) }}$

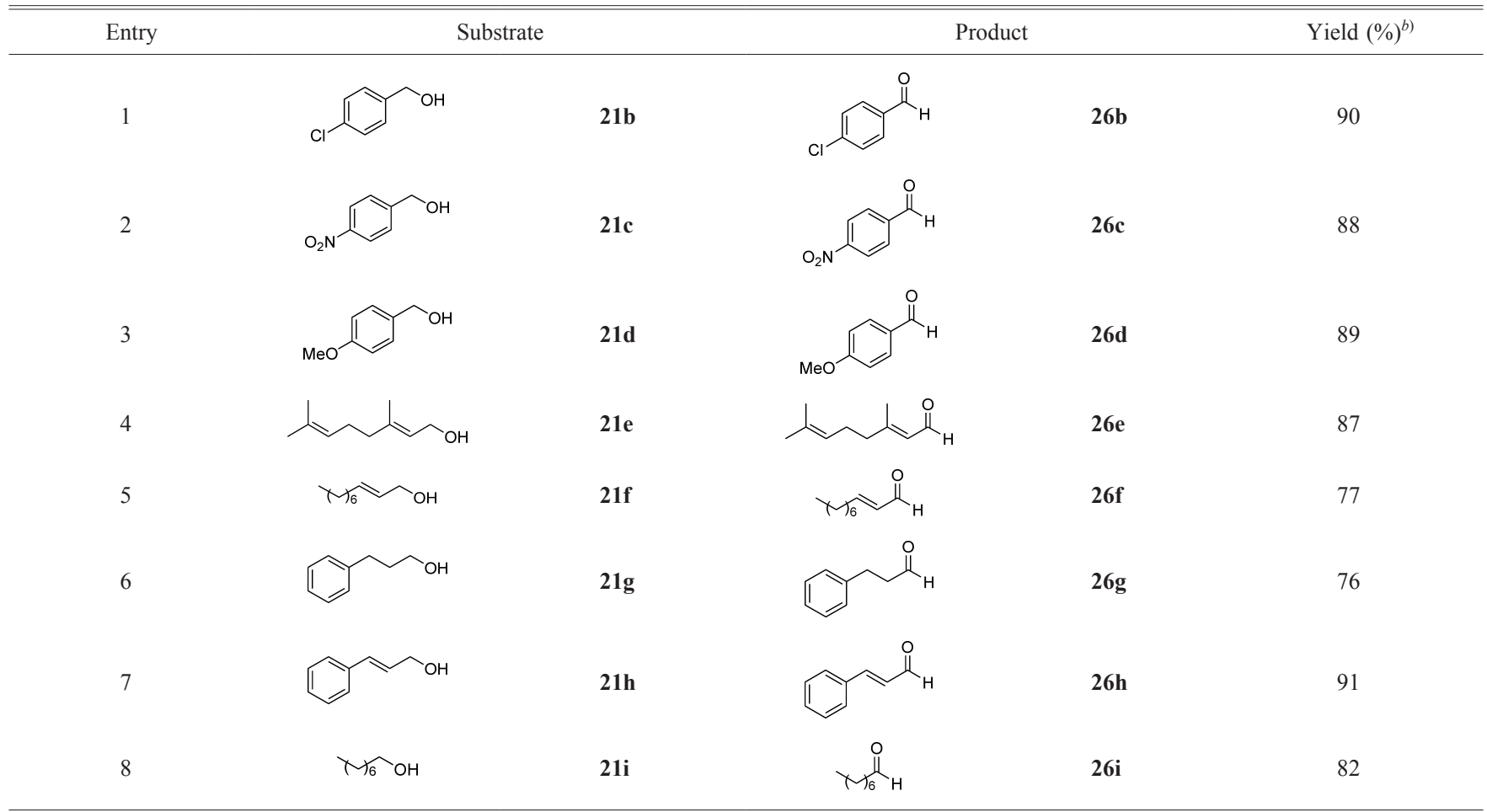

a) Condition: 25b (2-5 mol\%), toluene or (trifluoromethyl)benzene $\left.\mathrm{O}_{2}(1 \mathrm{~atm}), 80^{\circ} \mathrm{C}(2-8 \mathrm{~h}) . b\right)$ Yield of isolated products.

ease of catalyst recovering in catalytic oxidation that uses hydrogen peroxide or oxygen gas $\left(\mathrm{O}_{2}\right)$ as primary oxidant. In addition, the recovered solid-phase catalyst could be used for consecutive reactions without any significant loss of its catalytic efficacy.

The results described herein will enhance the utility of oxometalate and polyoxometalate catalysts in the field of organic synthesis. Further application of these methods would contribute to scientific development in the synthesis of fine chemicals and pharmaceuticals. Moreover, recent evolution of polymer sciences shows promise for the creation of more excellent catalysts in future.

Acknowledgments All the results described in this review were obtained at Osaka University, Teikyo University, and Kinki University. I would like to express my sincere appreciation to Professor Emeritus Yasuyuki Kita (Osaka University) and Professor Emeritus Shiro Ikegami (Teikyo University) for their continuous support and valuable advice on this research. I also want to express my thanks to Professor Yasuyoshi Miki (Kinki University), Professor Hideaki Natsugari (Teikyo University), Professor Hideyo Takahashi (Teikyo University), and Dr. Hirofumi Tohma for their helpful discussions. The research reviewed in this paper was possible only through the dedication, enthusiasm, and creativity of all my coworkers, whose names are acknowledged in the publications from our laboratory cited herein. This work was partially supported by a Grant-in-Aid for Scientific Research from the Ministry of Education, Culture, Sports, Science and Technology of Japan, Kinki University Research Grant Project, and also in part "High-Tech Research Center Project" for Private Universities and matching fund subsidy. 


\section{References and Notes}

1) Hudlicky M., "Oxidations in Organic Chemistry," ACS Monograph, Ser. 186, American Chemical Society, Washington, DC, 1990.

2) Sheldon R. A., "New Developments in Selective Oxidation (Studies in Surface Science and Catalysis 55)," ed. by Centi G., Trifiro F., Elsevier, Amsterdam, 1990, pp. 1-32.

3) “Comprehensive Organic Synthesis," 1st ed., Vol. 7, ed. by Trost B., M., Fleming I., Pergamon Press, Oxford, 1991.

4) "Modern Oxidation Methods," ed. by Bäckvall J.-E., Wiley-VCH, Weinheim, 2004.

5) Clark J. H., Macquarrie D. J., Org. Process Res. Dev., 1, 149-162 (1997).

6) "Metal-Catalyzed Oxidations of Organic Compounds," ed. by Sheldon R. A., Kochi J. K., Academic Press, New York, 1981.

7) "Metal Oxide Catalysis," ed. by Jackson S. D., Hargreaves J. S. J., Wiley-VCH, Weinheim, 2008.

8) "Modern Heterogeneous Oxidation Catalysis," ed. by Mizuno N., Wiley-VCH, Weinheim, 2009.

9) Tsigdinos G. A., Top. Curr. Chem., 76, 1-64 (1978).

10) Kozhevnikov I. V., Matveev K. I., Appl. Catal., 5, 135-150 (1983).

11) Misono M., Catal. Rev.: Sci. Eng., 29, 269-321 (1987).

12) Kozhevnikov I. V., Catal. Rev.: Sci. Eng., 37, 311-352 (1995).

13) Okuhara T., Mizuno N., Misono M., Adv. Catal., 41, 113-252 (1996).

14) Grate J. H., J. Mol. Catal. A: Chem., 114, 93-101 (1996).

15) Kozhevnikov I. V., Chem. Rev., 98, 171-198 (1998).

16) Mizuno N., Misono M., Chem. Rev., 98, 199-218 (1998).

17) Misono M., Ono I., Koyano G., Aoshima A., Pure Appl. Chem., 72, 1305-1311 (2000).

18) Okuhara T., Mizuno N., Misono M., Appl. Catal., 222, 63-77 (2001).

19) Misono M., Chem. Commun. (Camb.), 2001, 1141-1152 (2001).

20) Okuhara T., Chem. Rev., 102, 3641-3665 (2002).

21) Timofeeva M. N., Appl. Catal., A, 256, 19-35 (2003).

22) Mizuno N., Yamaguchi K., Chem. Rec., 6, 12-22 (2006).

23) Hill C. L., J. Mol. Catal. A: Chem., 262, 2-6 (2007).

24) Kozhevnikov I. V., J. Mol. Catal. A: Chem., 262, 86-92 (2007).

25) Ueda T., Kotsuki H., Heterocycles, 76, 73-97 (2008).

26) Zhizhina E. G., Odyakov V. F., Simonova M. V., Kinet. Catal., 49, 773-781 (2008).

27) Kozhevnikov I. V., J. Mol. Catal. A: Chem., 305, 104-111 (2009).

28) Qiao Y., Hou Z., Curr. Org. Chem., 13, 1347-1365 (2009).

29) Kholdeeva O. A., Marksimchuk N. V., Maksimov G. M., Catal. Today, 157, 107-113 (2010).

30) "Catalysts for Fine Chemicals, Catalysis by Polyoxometalates," Vol. 2, ed. by Kozhevnikov I. V., Wiley, Chichester, 2002.

31) Misono M., Nojiri N., Appl. Catal., 64, 1-30 (1990).

32) Nojiri N., Misono M., Appl. Catal., 93, 103-122 (1993).

33) "Heteropoly and Isopoly Oxometalates," ed. by Pope M. T., Springer, Berlin, 1983.

34) "Polyoxometalate Chemistry from Topology via Selfassembly to Applications," ed. by Pope M. T., Muller A., Kluwer, Dordrecht, 2001.

35) Misono M., Okuhara T., Chemtech, 23, 23-29 (1993).

36) The acid strength of Keggin HPAs decreases in the order: $\mathrm{H}_{3} \mathrm{PW}_{12} \mathrm{O}_{40}>\mathrm{H}_{4} \mathrm{SiW}_{12} \mathrm{O}_{40}>\mathrm{H}_{3} \mathrm{PMo}_{12} \mathrm{O}_{40}>\mathrm{H}_{4} \mathrm{SiMo}_{12} \mathrm{O}_{40}$.

37) "Zeolite, Clay, and Heteropoly Acid in Organic Reactions," ed. by Izumi Y., Urabe K., Onaka M., Kodansha-VCH, Tokyo, 1992.

38) The softness of heteropolyanion in aqueous solution was estimated as follows: $\mathrm{SiW}_{12} \mathrm{O}_{40}^{4-}>\mathrm{H}_{3} \mathrm{PW}_{12} \mathrm{O}_{40}^{3-}>\mathrm{H}_{4} \mathrm{H}_{3} \mathrm{PMo}_{12} \mathrm{O}_{40}^{3-}>\mathrm{H}_{4} \mathrm{SiMo}_{12} \mathrm{O}_{40}^{4-}$.

39) "Hypervalent Iodine Chemistry," ed. by Wirth T., Springer, Berlin, 2003 (Top. Curr. Chem., Vol. 224).

40) Banks D. F., Chem. Rev., 66, 243-266 (1966).

41) Varvoglis A., Chem. Soc. Rev., 10, 377-407 (1981).

42) Varvoglis A., Synthesis, 1984, 709-726 (1984).
43) Moriarty R. M., Prakash O., Acc. Chem. Res., 19, 244-250 (1986).

44) Moriarty R. M., Valid R. K., Koser G. F., Synlett, 1990, 365-383 (1990).

45) “The Organic Chemistry of Polycoordinated Iodine," ed. by Varvoglis A., VCH, New York, 1992.

46) Stang P. J., Angew. Chem. Int. Ed. Engl., 31, 274-285 (1992).

47) Stang P. J., Zhdankin V. V., Chem. Rev., 96, 1123-1178 (1996).

48) "Hypervalent Iodine in Organic Synthesis," ed. by Varvoglis A., Academic Press, San Diego, 1997.

49) Varvoglis A., Tetrahedron, 53, 1179-1255 (1997).

50) Kitamura T., Fujiwara Y., Org. Prep. Proced. Int., 29, 409-458 (1997).

51) Wirth T., Hirt U. H., Synthesis, 1999, 1271-1287 (1999).

52) Togo H., Katohgi M., Synlett, 2001, 565-581 (2001).

53) Zhdankin V. V., Stang P. J., Chem. Rev., 102, 2523-2584 (2002).

54) Minatti A., Synlett, 2003, 140-141 (2003).

55) Moriarty R. M., J. Org. Chem., 70, 2893-2903 (2005).

56) Wirth T., Angew. Chem., Int. Ed., 44, 3656-3665 (2005).

57) Zhdankin V. V., Stang P. J., Chem. Rev., 108, 5299-5358 (2008).

58) Uyanik M., Ishihara K., Chem. Commun. (Camb.), 2009, 20862099 (2009).

59) Hamamoto H., Umemoto H., Umemoto M., Ohta C., Dohshita M., Miki Y., Synlett, 2010, 2593-2596 (2010).

60) Hamamoto H., Hattrori S., Takemaru K., Miki Y., Synlett, 2011, 1563-1565 (2011).

61) Kita Y., Tohma H., Yakura T., Trends Org. Chem., 3, 113-128 (1992).

62) Kita Y., Tohma H., Farumasia, 28, 984 (1992).

63) Kita Y., Takada T., Tohma H., Pure Appl. Chem., 68, 627-630 (1996).

64) Tohma H., Yakugaku Zasshi, 120, 620-629 (2000), Commemorative Review for the Pharmaceutical Society of Japan Award for Young Scientists.

65) Arisawa M., Tohma H., Kita Y., Yakugaku Zasshi, 120, 1061-1073 (2000).

66) Kita Y., Yakugaku Zasshi, 122, 1011-1035 (2002), Commemorative Review for the Pharmaceutical Science of Japan Award.

67) Tohma H., Kita Y., Top. Curr. Chem., 224, 209-248 (2003).

68) Hamamoto H., Tohma H., Kita Y., FIU Lett., 6, 115-127 (2003).

69) Tohma H., Kita Y., Adv. Synth. Catal., 346, 111-124 (2004).

70) Tohma H., Kita Y., J. Synth. Org. Chem. Jpn., 62, 116-127 (2004).

71) Dohi T., Kita Y., Kagaku (Kyoto), 61, 68-69 (2006).

72) Kita Y., Kagaku Kogyo, 59, 16-22 (2008).

73) Dohi T., Kita Y., Chem. Commun. (Camb.), 2009, 2073-2085 (2009).

74) Dohi T., Ito M., Yamaoka N., Morimoto K., Fujioka H., Kita Y., Tetrahedron, 65, 10797-10815 (2009).

75) Kita Y., Dohi T., Fain Kemikaru, 40, 49-55 (2011).

76) Kita Y., Dohi T., Morimoto K., Kagaku (Kyoto), 66, 12-18 (2011).

77) Kita Y., Dohi T., Morimoto K., Yuki Gosei Kagaku Kyokaishi, 69, 1241-1250 (2011).

78) Tamura Y., Yakura T., Haruta J., Kita Y., Tetrahedron Lett., 26, 3837-3840 (1985).

79) Tamura Y., Yakura T., Haruta J., Kita Y., J. Org. Chem., 52, $3927-$ 3930 (1987).

80) Tamura Y., Yakura T., Tohma H., Kikuchi Y., Kita Y., Synthesis, 1989, 126-127 (1989).

81) Kita Y., Yakura T., Tohma H., Kikuchi Y., Tamura Y., Tetrahedron Lett., 30, 1119-1120 (1989).

82) Kita Y., Tohma H., Kikuchi Y., Inagaki M., Yakura T., J. Org. Chem., 56, 435-438 (1991).

83) Kita Y., Tohma H., Inagaki M., Hatanaka K., Yakura T., Tetrahedron Lett., 32, 4321-4324 (1991).

84) Kita Y., Tohma H., Inagaki M., Hatanaka K., Yakura T., J. Am. Chem. Soc., 114, 2175-2180 (1992).

85) Kita Y., Okunaka R., Kondo M., Tohma H., Inagaki M., Hatanaka 
K., J. Chem. Soc., Chem. Commun., 1992, 429-430 (1992).

86) Kita Y., Tohma H., Hatanaka K., Takada T., Fujita S., Mitoh S., Sakurai H., Oka S., J. Am. Chem. Soc., 116, 3684-3691 (1994).

87) Kita Y., Takada T., Mihara S., Tohma H., Synlett, 1995, 211-212 (1995).

88) Kita Y., Takada T., Ibaraki M., Gyoten M., Mihara S., Fujita S., Tohma H., J. Org. Chem., 61, 223-227 (1996).

89) Kita Y., Gyoten M., Ohtsubo M., Tohma H., Takada T., Chem. Commun. (Camb.), 1996, 1481-1482 (1996).

90) Kita Y., Egi M., Okajima A., Ohtsubo M., Takada T., Tohma H., Chem. Commun. (Camb.), 1996, 1491-1492 (1996).

91) Kita Y., Egi M., Ohtsubo M., Saiki T., Takada T., Tohma H., Chem. Commun. (Camb.), 1996, 2225-2226 (1996).

92) Kita Y., Takada T., Gyoten M., Tohma H., Zenk M. H., Eichhorn J., J. Org. Chem., 61, 5857-5864 (1996).

93) Kita Y., Arisawa M., Gyoten M., Nakajima M., Tohma H., Takada T., J. Org. Chem., 63, 6625-6633 (1998).

94) Takada T., Arisawa M., Gyoten M., Hamada R., Tohma H., Kita Y., J. Org. Chem., 63, 7698-7706 (1998).

95) Arisawa M., Utsumi S., Nakajima M., Ramesh N. G., Tohma H., Kita Y., Chem. Commun. (Camb.), 1999, 469-470 (1999).

96) Kita Y., Egi M., Takada T., Tohma H., Synthesis, 1999, 885-897 (1999).

97) Tohma H., Morioka H., Takizawa S., Arisawa M., Kita Y., Tetrahedron, 57, 345-352 (2001).

98) Tohma H., Harayama Y., Hashizume M., Iwata M., Kiyono Y., Egi M., Kita Y., J. Am. Chem. Soc., 125, 11235-11240 (2003).

99) Wada Y., Harayama Y., Kamimura D., Yoshida M., Shibata T., Fujiwara K., Morimoto K., Fujioka H., Kita Y., Org. Biomol. Chem., 9, 4959-4976 (2011).

100) Hamamoto H., Anilkumar G., Tohma H., Kita Y., Chem.-Eur. J., 8, 5377-5383 (2002).

101) Hamamoto H., Anilkumar G., Tohma H., Kita Y., Chem. Commun. (Camb.), 2002, 450-451 (2002).

102) For leading references on both the synthesis and natural occurrence of biaryls, see Bringmann G., Walter R., Weirich R., Angew. Chem. Int. Ed. Engl., 29, 977-991 (1990).

103) Kupchan S. M., Liepa A. J., Kameswaran V., Bryan R. F., J. Am. Chem. Soc., 95, 6861-6863 (1973).

104) Taylor E. C., Andrade J. G., Rall G. J. H., McKillop A., J. Am. Chem. Soc., 102, 6513-6519 (1980).

105) Landais Y., Rambaut D., Robin J. P., Tetrahedron Lett., 28, 543546 (1987).

106) Cambie R. C., Crow P. A., Rutledge P. S., Woodgate P. D., Aust. J. Chem., 41, 897-918 (1988).

107) Landais Y., Robin J. P., Tetrahedron, 48, 7185-7196 (1992).

108) Planchenault D., Dhal R., Robin J.-P., Tetrahedron, 49, 5823-5830 (1993).

109) Moreno I., Tellitu I., Herrero M. T., SanMartin R., Dominguez E., Curr. Org. Chem., 6, 1433-1452 (2002).

110) Izumi Y., Matsuo K., Urabe K., J. Mol. Catal. A: Chem., 18 299-314 (1983).

111) Dhingra O. P., "Oxidation in Organic Chemistry," Part D, ed. by Trahanovsky W. S., Academic Press, New York, 1982.

112) Barton D. H. R., Cohen T., "Festschrift A. Stoll," Birkhauser, Basel, 1957.

113) Wildman W. C., Fales H. M., Battersby A. R., J. Am. Chem. Soc., 84, 681-682 (1962).

114) Barton D. H. R., Kinby G. W., Taylor J. B., Thomas T. S., J. Chem. Soc., 1963, 4545-4558 (1963).

115) Paton J. M., Pauson P. L., Stevens T. S., J. Chem. Soc., 1969, 1309-1314 (1996)

116) Harbert R. B., Alkaloids, 1, 1-30 (1971).

117) Kametani T., Ohta Y., Takemura M., Ihara M., Fukumoto K., Bioorg. Chem., 6, 249-256 (1977).

118) Eichhorn J., Takada T., Kita Y., Zenk M. H., Phytochemistry, 49,
1037-1047 (1998).

119) Davidson T. A., Scott A. I., J. Chem. Soc., 1961, 4075-4078 (1961).

120) Gervay J. E., McCapara F., Money T., Sharma G. M., Scott A. I., J. Chem. Soc., Chem. Commun., 1966, 142-143 (1966).

121) Schwartz M. A., Holton R. A., Scott S. W., J. Am. Chem. Soc., 91, 2800-2801 (1969).

122) Schwartz M. A., Holton R. A., J. Am. Chem. Soc., 92, 1090-1092 (1970).

123) Schwartz M. A., Rose B. F., Vishnuvajjala B., J. Am. Chem. Soc., 95, 612-613 (1973).

124) Battersby A. R., Bradbury R. B., Herbert R. B., Munro M. H. G., Ramage R. J. Chem. Soc., Perkin Trans. 1, 1974, 1394-1399 (1974).

125) Schwartz M. A., Mami I. S., J. Am. Chem. Soc., 97, 1239-1240 (1975).

126) Kupchan S. M., Dhingra O. P., Kim C.-K., J. Org. Chem., 41 4049-4050 (1976)

127) Schwartz M. A., Rose B. F., Holton R. A., Scotto S. W., J. Am. Chem. Soc., 99, 2571-2579 (1977).

128) Tomioka K., Koga K., Yamada S., Chem. Pharm. Bull., 25, 26812688 (1977)

129) Shimizu K., Tomioka K., Yamada S., Koga K., Chem. Pharm. Bull., 26, 3765-3771 (1978).

130) Kupchan S. M., Dhingra O. P., Kim C.-K., J. Org. Chem., 43, 4076-4081 (1978)

131) Schwartz M. A., Pham P. T. K., J. Org. Chem., 53, 2318-2322 (1988).

132) Lewis N., Wallbank P., Synthesis, 1987, 1103-1106 (1987).

133) Pelter A., Elgendly S., Tetrahedron Lett., 29, 677-680 (1988).

134) Pelter A., Elgendly S., J. Chem. Soc., Perkin Trans. 1, 1993, 18911892 (1993)

135) Fleck A. E., Hobart J. A., Morrow G. W., Synth. Commun., 22, 179-187 (1992).

136) Mitchell A. S., Russell R. A., Tetrahedron Lett., 34, 545-548 (1993).

137) Sainsbury M., Tetrahedron, 36, 3327-3359 (1980).

138) Stuart K. L., Chem. Rev., 71, 47-72 (1971).

139) Kametani T., Fukumoto K., J. Heterocycl. Chem., 8, 341-357 (1971).

140) Kametani T., Fukumoto K., Acc. Chem. Res., 5, 212-219 (1972).

141) Kametani T., Fukumoto K., Synthesis, 1972, 657-674 (1972).

142) Blaskó G., Cordell G. A., Heterocycles, 27, 1269-1300 (1988).

143) Kametani T., Fukumoto K., Satoh F., Bioorg. Chem., 3, 430-497 (1974).

144) Franck B., Dunkelmann G., Lubs H. J., Angew. Chem. Int. Ed. Engl., 6, 1075-1076 (1967).

145) Blaskó G., Dörnyel G., Bárczai-Bake M., Péchy P., Szántay C., J. Org. Chem., 49, 1439-1441 (1984).

146) Hara H., Komoriya S., Miyashita T., Hoshino O., Tetrahedron Asymmetry, 6, 1683-1692 (1995).

147) Miller L. L., Stermitz F. R., Falck J. R., J. Am. Chem. Soc., 93, 5941-5942 (1971).

148) Miller L. L., Stermitz F. R., Falck J. R., J. Am. Chem. Soc., 95, 2651-2656 (1973).

149) Klünenberg H., Schäffer C., Schäfer H.-J., Tetrahedron Lett., 23, 4581-4584 (1982).

150) Bentley T. W., Morris S. J., J. Org. Chem., 51, 5005-5007 (1986).

151) Kupchan S. M., Kameswaran V., Lynn J. T., Williams D. K., Liepa A. J., J. Am. Chem. Soc., 97, 5622-5623 (1975).

152) Kupchan S. M., Dhingra O. P., Kim C.-K., Kameswaran V., J. Org. Chem., 43, 2521-2529 (1978).

153) Hamamoto H., Shiozaki Y., Nambu H., Hata K., Tohma H., Kita Y., Chem.-Eur. J., 10, 4977-4982 (2004).

154) Hamamoto H., Shiozaki Y., Hata K., Tohma H., Kita Y., Chem. Pharm. Bull., 52, 1231-1234 (2004).

155) The following acid additives were examined and $\mathrm{BF}_{3} \cdot \mathrm{Et}_{2} \mathrm{O}$ was the most efficient acid additive for this reaction; $\mathrm{BF}_{3} \cdot \mathrm{Et}_{2} \mathrm{O}, \mathrm{FSO}_{3} \mathrm{H}$, 
TfOH, TMSOTf, $\mathrm{H}_{2} \mathrm{SO}_{4}$ (98\%), $\mathrm{HBF}_{4}(42 \%), \mathrm{CF}_{3} \mathrm{CO}_{2} \mathrm{H}$, Nafion- $\mathrm{H}$ and Montmollironite K10.

156) Kozhevnikov I. V., Kloetstra K. R., Sinnema A., Zandbergen H. W., van Bekkum H., J. Mol. Catal. A.: Chem., 114, 287-298 (1996).

157) Rao A. V. R., Gurjar M. K., Sharma P. A., Tetrahedron Lett., 32, 6613-6616 (1991).

158) Wipf P., Kim Y., Tetrahedron Lett., 33, 5477-5480 (1992).

159) Wipf P., Kim Y., Fritch P. C., J. Org. Chem., 58, 7195-7203 (1993).

160) Takagi R., Miyanaga W., Tamura Y., Ohkata K., Chem. Commun. (Camb.), 2002, 2096-2097 (2002).

161) Davies J. S., Hassall C. H., Schofield J. A., J. Chem. Soc., 1964, 3126-3132 (1964).

162) Corey E. J., Huefele L. F., J. Am. Chem. Soc., 81, 2225-2228 (1959).

163) Scott A. I., Dodson P. A., McCapra F., Meyers M. B., J. Am. Chem. Soc., 85, 3702-3705 (1963).

164) Tamura Y., Yakura T., Haruta J., Kita Y., J. Org. Chem., 52, $3927-$ 3930 (1987).

165) Taylor E. C., Andrade J. G., Rall G. J. H., Turchi I. J., Steliou K., Jagdmann G. E. Jr., McKillop A., J. Am. Chem. Soc., 103, 68566863 (1981).

166) Hata K., Hamamoto H., Shiozaki Y., Kita Y., Chem. Commun. (Camb.), 2005, 2465-2467 (2005).

167) Hamamoto H., Hata K., Nambu H., Shiozaki Y., Tohma H., Kita Y., Tetrahedron Lett., 45, 2293-2295 (2004).

168) Hata K., Hamamoto H., Shiozaki Y., Cämmerer S. B., Kita Y., Tetrahedron, 63, 4052-4060 (2007).

169) Inada A., Murata H., Tanaka K., Somekawa M., Nakazawa T., Nishi M., Nakanishi T., Shoyakugaku Zasshi, 47, 301-304 (1993).

170) Román L. U., Cambrón J. I., del Río R. E., Hernández J. D., CerdaGarcía-Rojas C. M., Joseph-Nathan P., J. Nat. Prod., 63, 226-229 (2000).

171) Al-Musayeib N. M., Abbas F. A., Ahmad M. S., Mossa J. S., ElFeraly F. S., Phytochemistry, 54, 771-775 (2000).

172) Gladysz J. A., Pure Appl. Chem., 73, 1319-1324 (2001).

173) Kragl U., Dwars T., Trends Biotechnol., 19, $442-449$ (2001).

174) Tzschucke C. C., Market C., Bannwarth W., Roller S., Hebel A., Haag R., Angew. Chem., Int. Ed., 41, 3964-4000 (2002).

175) Gladysz J. A., Chem. Rev., 102, 3215-3216 (2002).

176) Cole-Hamilton D. J., Science, 299, 1702-1706 (2003).

177) Shuttleworth S., Allin S. M., Wilson R. D., Nasturica D., Synthesis, 2000, 1035-1074 (2000).

178) Clapham B., Reger T. S., Janda K. D., Tetrahedron, 57, 4637-4662 (2001).

179) Kirschning A., Monenschein H., Wittenberg R., Angew. Chem., Int. Ed., 40, 650-679 (2001).

180) Kobayashi S., Akiyama R., Chem. Commun. (Camb.), 2003, 449 460 (2003).

181) Kirschning A., Jas G., Top. Curr. Chem., 242, 209-239 (2004).

182) Behr A., Henze G., Schomaecker R., Adv. Synth. Catal., 348, 1485-1495 (2006).

183) Sheldon R. A., Green Chem., 7, 267-278 (2005).

184) Jessop P. G., Heldebrant D. J., Li X., Eckert C. A., Liotta C. L., Nature (London), 436, 1102 (2005).

185) Afonso C. A. M., Branco L. C., Candeias N. R., Gois P. M. P., Lourenco N. M. T., Mateus N. M. M., Rosa J. N., Chem. Commun. (Camb.), 2007, 2669-2679 (2007).

186) Welton T., Chem. Rev., 99, 2071-2084 (1999).

187) Earle M. J., Seddon K. R., Pure Appl. Chem., 72, 1391-1398 (2000).

188) Wasserscheid P., Keim W., Angew. Chem., Int. Ed., 39, 3772-3789 (2000).
189) Dupont J., de Souza R. F., Suarez P. A. Z., Chem. Rev., 102, 36673692 (2002).

190) Sheldon R. A., Chem. Commun. (Camb.), 2001, 2399-2407 (2001).

191) Handy S. T., Chem.-Eur. J., 9, 2938-2944 (2003).

192) Jain N., Kumar A., Chauhan S., Chauhan S. M. S., Tetrahedron, 61, 1015-1060 (2005).

193) Heintz A., Wertz C., Pure Appl. Chem., 78, 1587-1593 (2006).

194) Afonso C. A. M., Branco L. C., Candeias N. R., Gois P. M. P., Lourenco N. M. T., Mateus N. M. M., Rosa J. N., Chem. Commun. (Camb.), 2007, 2669-2679 (2007).

195) Binnemans K., Chem. Rev., 107, 2592-2614 (2007).

196) Pârvulescu V. I., Hardacre C., Chem. Rev., 107, 2615-2665 (2007).

197) Weingaertner H., Angew. Chem., Int. Ed., 47, 654-670 (2008).

198) Horváth I. T., Rábai J., Science, 266, $72-75$ (1994).

199) Studer A., Hadida S., Ferritto R., Kim S.-Y., Jeger P., Wipf P., Curran D. P., Science, 275, 823-826 (1997).

200) Cornils B., Angew. Chem. Int. Ed. Engl., 36, 2057-2059 (1997).

201) Horvath I. T., Acc. Chem. Res., 31, 641-650 (1998).

202) Curran D. P., Pure Appl. Chem., 72, 1649-1653 (2000).

203) Kitazume T., J. Fluorine Chem., 105, 265-278 (2000).

204) Luo Z., Zhang Q., Oderaotoshi Y., Curran D. P., Science, 291, 1766-1769 (2001).

205) Gladysz J. A., Curran D. P., Tetrahedron, 58, 3823-3825 (2002).

206) Sandford G., Tetrahedron, 59, 437-454 (2003).

207) Schild H. G., Prog. Polym. Sci., 17, 163-249 (1992).

208) Heskins M., Guillet J. E., J. Macromol. Sci. Chem., A2, 1441-1455 (1968).

209) Hamamoto H., Yuki Gosei Kagaku Kyokaishi, 66, 253 (2008).

210) Bergbreiter D. E., Chem. Rev., 102, 3345-3384 (2002).

211) Bergbreiter D. E., Hughes R., Besinaiz J., Li C., Osburn P. L., J. Am. Chem. Soc., 125, 8244-8249 (2003).

212) Bergbreiter D. E., Li J., Top. Curr. Chem., 242, 113-176 (2004).

213) Bergbreiter D. E., Sung S. D., Adv. Synth. Catal., 348, 1352-1366 (2006).

214) Hamamoto H., Ikegami S., Yuki Gosei Kagaku Kyokaishi, 66, 205-214 (2008).

215) Ikegami S., Hamamoto H., Chem. Rev., 109, 583-593 (2009).

216) Hamamoto H., Suzuki Y., Yamada Y. M. A., Tabata H., Takahashi H., Ikegami S., Angew. Chem., Int. Ed., 44, 4536-4538 (2005).

217) Hamamoto H., Kudoh M., Takahashi H., Ikegami S., Org. Lett., 8 , 4015-4018 (2006).

218) Hamamoto H., Suzuki Y., Takahashi H., Ikegami S., Tetrahedron Lett., 48, 4239-4242 (2007).

219) Hamamoto H., Kudoh M., Takahashi H., Natsugari H., Ikegami S., Chem. Lett., 36, 632-633 (2007).

220) Hamamoto H., Suzuki Y., Takahashi H., Ikegami S., Adv. Synth. Catal., 349, 2685-2689 (2007).

221) Yamada Y. M. A., Chem. Pharm. Bull., 53, $723-739$ (2005).

222) Yamada Y. M. A., Ichinohe M., Takahashi H., Ikegami S., Org. Lett., 3, 1837-1840 (2001).

223) Yamada Y. M. A., Takeda K., Takahashi H., Ikegami S., Org. Lett., 4, 3371-3374 (2002).

224) Yamada Y. M. A., Tabata H., Ichinohe M., Takahashi H., Ikegami S., Tetrahedron, 60, 4087-4096 (2004).

225) Schwuger M.-J., Stickdorn K., Schomäcker R., Chem. Rev., 95, 849-864 (1995).

226) Tascioglu S., Tetrahedron, 52, 11113-11152 (1996).

227) Ishii Y., Yamawaki K., Ura T., Yamada H., Yoshida T., Ogawa M., J. Org. Chem., 53, 3591-3593 (1988).

228) Plault L., Hauseler A., Nlate S., Astruc D., Ruiz J., Gatard S., Neumann R., Angew. Chem., Int. Ed., 43, 2924-2928 (2004). 